\title{
ANÁLISIS COMPARADO DE LOS REGISTROS DE LA PROPIEDAD ALEMÁN Y ESPAÑOL: ¿SERÍA POSIBLE UN REGISTRO DE LA PROPIEDAD COMÚN EUROPEO?
}

\section{COMPARATIVE ANALYSIS OF THE GERMAN AND SPANISH PROPERTY REGISTRIES: WOULD A EUROPEAN COMMON PROPERTY REGISTER BE POSSIBLE?}

\author{
Alena Veronica Horvath \\ Graduada en el Doble Grado en Derecho Hispano-Alemán \\ por las Universidades Pablo de Olavide de Sevilla y Bayreuth \\ Juan Pablo Pérez VelázQuez \\ Profesor Ayudante Doctor de Derecho Civil de la Universidad Pablo de Olavide \\ de Sevilla (Acreditado a Profesor Contratado Doctor)
}

Recibido: 15.06.2021 / Aceptado: 06.07.2021

DOI: https://doi.org/10.20318/cdt.2021.6267

\begin{abstract}
Resumen: Sobre la base de un análisis comparado de los Registros de la Propiedad alemán y español, el objetivo de este trabajo es abordar el estudio de la viabilidad de crear un Registro de la Propiedad Común Europeo, que elimine las incertidumbres que genera que un ciudadano comunitario adquiera un bien inmueble en otro país de la Unión Europea, otorgando seguridad jurídica en el tráfico inmobiliario. En definitiva, configurar un sistema registral transfronterizo comunitario, que agilice y otorgue seguridad jurídica a la transmisión de bienes inmuebles.

Palabras clave: derechos reales, transmisión, Registro de la Propiedad, Registro de la Propiedad Común Europeo.

Abstract: Based on a comparative analysis of the German and Spanish Property Registries, the aim of this paper is to tackle the study of the feasibility of creating a European Common Property Registry, which eliminates the uncertainties generated when a community citizen acquire a real estate in another country of the European Union, granting legal certainty in real estate traffic. In short, it's about configuring a community cross-border registration system, which streamlines and grants legal certainty to the transfer of real estate.

Keywords: real property rights, transmission, Property Registry, European Common Property Registry.
\end{abstract}

Sumario: I. Introducción. II. Planteamiento. 1. Principios básicos de los derechos reales. 2. Aspectos generales del derecho inmobiliario registral. III. Análisis comparado del Derecho alemán y español. 1. Régimen de transmisión de los derechos reales. A) En Alemania: principio de separación y abstracción. Acuerdo e inscripción. B. En España: teoría del título y el modo. C). Resultado de la comparación del derecho material. 2. Aspectos formales del Registro de la Propiedad. A) Organización y estructura en Alemania y España. B). Requisitos formales de la inscripción en Alemania y España. C). Publicidad formal en Alemania y España. 3. Derecho inmobiliario material en Alemania. A). Valor y efectos de la inscripción. B). Fe pública registral. 4. Derecho inmobiliario 
material en España. A). Valor y efectos de la inscripción. 5. Conclusiones de la comparación. IV. El establecimiento de un Registro de la Propiedad Común Europeo. 1. Draft Common Frame of Reference (DCFR). 2. Integración positiva y negativa. 3. European Land Information Service (EULIS). 4. Competencia legislativa de la Unión Europea en derecho inmobiliario registral. 5. Perspectivas. A) Perspective and Feasibility \& Implementation Analysis (2014). B). Directiva (UE) 2018/843 del Parlamento Europeo y del Consejo, de 30 de mayo de 2018. C) Técnica legislativa adecuada. D) Posible configuración. E) Viabilidad. V. Conclusiones finales.

\section{Introducción}

1. Todo ciudadano europeo es libre en decidir dónde quiere trabajar y vivir. Este es uno de los principios esenciales de la Unión Europea que, en el Tratado de Maastricht, estableció cuatro libertades fundamentales: la libre circulación de personas, capitales, bienes y servicios. Parece ello ser una buena base para facilitar transacciones inmobiliarias transfronterizas, como la compra de un bien inmueble en el ámbito de la Unión Europea. La pregunta que suscita lo anterior es cuáles son las dificultades que se pueden plantear en la práctica.

2. Superadas las fronteras terrestres nacionales dentro de la Unión Europea, las legales, debidas a las diferencias entre los Ordenamientos civiles, siguen estando presentes y provocan dificultades fácticas y legales. Un elemento esencial en la compra de un inmueble es la accesibilidad a la información acerca del mismo. Por este motivo, la mayoría de los países europeos tienen un Registro para publicar los datos relevantes de los inmuebles, configurándolo cada uno según sus propias reglas.

3. Planteemos un ejemplo: un ciudadano alemán, Sr. Müller, desea comprar una residencia sita en Málaga al Sr. García. En primer lugar, ¿dónde puede el Sr. Müller obtener información relevante y cómo la puede consultar? Una vez que la haya obtenido, ¿qué valor legal tiene? Si el Sr. García tiene inscrito como propietario el inmueble, ¿significa ello que es en todo caso legítimo titular del mismo y tiene el necesario poder de disposición? ¿O puede ser que existan otros derechos no inscritos sobre dicho inmueble?

4. Estas incertidumbres surgen mayoritariamente de las diferencias entre los distintos sistemas registrales nacionales, que dificultan la adquisición de un inmueble en otro país europeo, convirtiéndolo en un negocio jurídico de riesgo.

5. Sobre la base de una comparación del Registro de la Propiedad alemán, el Grundbuch, y el Registro de la Propiedad español, el presente trabajo tiene por objeto preguntarse, e intentar de ofrecer una solución a la posibilidad de crear un Registro de la Propiedad Común Europeo que elimine tales incertidumbres, otorgando seguridad jurídica en el tráfico inmobiliario. En definitiva, un sistema registral transfronterizo, que, bajo ese principio de seguridad jurídica, agilizara la transmisión de bienes inmuebles.

\section{Planteamiento}

\section{Principios básicos de los derechos reales}

6. Para entender la necesidad o, a mejor decir, las ventajas de establecer un Registro de la Propiedad Común Europeo, es imprescindible conocer las razones que en su momento motivaron su instauración a nivel nacional. Por este motivo, enunciamos a continuación las características básicas de los derechos reales, decisivas en el marco de este trabajo. 
7. Los derechos reales son derechos absolutos ${ }^{1}$. Esto significa que el propietario de un bien tiene el pleno dominio sobre el mismo y la facultad de excluir a cualquier tercero que no reconozca su posición jurídico-real o le perturbe en el ejercicio de sus derechos sobre la cosa ${ }^{2}$. En comparación con el derecho de crédito, que se caracteriza por su relatividad y eficacia inter partes, el derecho real tiene eficacia erga omnes, es decir, que es oponible frente a todos ${ }^{3}$. El titular real goza de una amplia protección legal de su posición jurídica ${ }^{4}$.

8. Del alcance absoluto de los derechos reales surge la necesidad primordial de darles cognoscibilidad legal, tanto en su existencia como en su pertenencia ${ }^{5}$. Lo anterior conforma el denominado "principio de la publicidad registral". Solo sería procedente conectar consecuencias jurídicas a una perturbación de la posición jurídico-real de otra persona, si el perturbador tiene la posibilidad de conocer la situación de dominio de aquélla ${ }^{7}$. Dado que la titularidad sobre un derecho real por sí no es externamente evidente, el Ordenamiento jurídico ha de tipificar o crear signos externos que permiten identificar la relación jurídica que alguien tiene con una $\cos ^{8}$.

9. La manifestación de esos signos externos, nos llevan al estudio del concepto de posesión y de la publicidad registral, para lo que se instrumenta el Registro de la Propiedad.

10. En este sentido, con limitación a las cosas muebles, se recurre a la posesión como signo externo, puesto que, con alguna probabilidad, el poseedor es también titular de la cosa ${ }^{9}$. La transmisión de cosas muebles está por lo tanto basada en la tradición; acto a través del cual el adquirente toma posesión del bien y da publicidad a la nueva situación ${ }^{10}$.

11. Pero, por otra parte, para identificar al propietario de un bien inmueble, el signo de la posesión resulta por sí solo inadecuado. Una casa o un piso pueden encontrarse en posesión de un arrendatario mientras que el arrendador continúa siendo titular del mismo ${ }^{11}$. Además, la posesión, por sí sola no permite reconocer derechos reales de garantía que graven el bien inmueble ${ }^{12}$. Así, el signo de la posesión no es suficiente como mecanismo de exteriorización, y puede incluso inducir a los intervinientes en el tráfico jurídico a errores al adquirir un bien del poseedor que carezca de legitimación y poder de disposición ${ }^{13}$.

${ }^{1}$ F. J. SÁnchez Calero / B. Moreno Quesada, Curso de Derecho Civil III, Derechos reales y registral inmobiliario, 8 a Edición, Tirant lo Blanch, Valencia 2019, p. 105; K. SCHREIBER, "Die Grundprinzipien des Sachenrechts", JURA, 2010, pp. 272 y 273.

${ }^{2}$ M. Albaladejo, Derecho Civil III. Derecho de Bienes, $10^{a}$ Edición, Bosch, Barcelona 2004, § 1.3; J. R. Verda y Beamonte / A. Serra Rodríguez / M. L. Atienza Navarro, Derecho civil III (Derechos reales), Tirant Lo Blanch, $5^{a}$ Edición, Valencia 2019, p. 20; K. SChreIBER, "Die Grundprinzipien des Sachenrechts", cit. pp. 272 y 273; J. F. BAUR/ R. STÜRnER, Sachenrecht, 18, Auflage, München, 2009, § 4 apdo 3; K. Vieweg / A. Werner, Sachenrecht, 7. Auflage, München 2015, § 1 apdo 6; J. L. LACRUZ Berdejo / J. Delgado Echeverría / J. J. Rams Albesa, Elementos de Derecho Civil. III bis, Derecho inmobiliario registral, $2^{\mathrm{a}}$ Edición, Madrid, 2003, p. 115.

${ }^{3}$ J. R. Verda y Beamonte / A. Serra Rodríguez / M. L. Atienza Navarro, Derecho civil III (Derechos reales), cit. p. 21; K. Schreiber, "Die Grundprinzipien des Sachenrechts", cit. pp. 272 y 273; K. VIEWEg / A. Werner, Sachenrecht, cit. § 1 apdo 6.

${ }^{4}$ J. R. Verda y Beamonte / A. Serra Rodríguez / M. L. Atienza Navarro, Derecho civil III (Derechos reales), cit. p. 20; K. SChreiber, "Die Grundprinzipien des Sachenrechts", cit. pp. 272 y 273.

${ }^{5}$ K. Vieweg / A. Werner, Sachenrecht, cit. § 1 apdo. 9; Wellenhofer, M., Sachenrecht, 32. Auflage, München 2017, § 3 apdo. 5; K. MüLLER / U. GruBER, Sachenrecht, München, 2016, § 5 apdo 69.

${ }^{6}$ K. SChreiber, "Die Grundprinzipien des Sachenrechts”, cit. pp., 272 y 274.

${ }^{7}$ Münchener Kommentar zum Bürgerlichen Gesetzbuch, 8. Auflage, München, 2020, apdo 22; K. VIEWEg / A. WeRnER, Sachenrecht, cit. § 1 apdo 9.

${ }^{8}$ C. S. Rupp, "Germanisches Grundbuch und romanisches Register: Harmonisierende Überlegungen”, Archiv für civilistische Praxis, 214 (2014), pp. 567 y 568; K. SchreIBER, "Die Grundprinzipien des Sachenrechts", cit. pp. 272 y 274.

${ }^{9}$ J. F. BAUR/ R. STÜRnER, Sachenrecht, cit. $§ 4$ apdo 9.

${ }^{10}$ J. R. Verda y Beamonte / A. Serra Rodríguez / M. L. Atienza Navarro, Derecho civil III (Derechos reales), p. 58 ; K. MÜLLER / U. Gruber, Sachenrecht, cit. § 5 apdo 70.

${ }^{11}$ H. PrÜtTING, Sachenrecht, 36. Auflage, München 2017, § 15 apdo 132.

${ }^{12}$ C. S. Rupp, "Germanisches Grundbuch und romanisches Register: Harmonisierende Überlegungen”, cit. p. 567.

${ }^{13}$ L. J. Arrieta Sevilla, "La finca registral como objeto del registro de la propiedad", en García García (coord.), Estudios sobre la representación gráfica de las fincas registrales, Pamplona, Aranzadi, 2018, pp. 29-48; R. WeBER, Sachenrecht II Grundstücksrecht, 4. Auflage, Baden-Baden 2015, § 4 apdo 6. 
12. Por consiguiente, el Ordenamiento jurídico ha de prever medios y mecanismos alternativos que garanticen proporcionar toda la información relevante sobre un bien inmueble ${ }^{14}$. Históricamente han existido medios de publicación muy diversos. En la Grecia Clásica, por ejemplo, se colocaban piedras indicando la existencia de un gravamen junto al inmueble que lo soportaba ${ }^{15}$. A partir del siglo XIX, tuvieron lugar la aparición de los Registros modernos, como el Grundbuch alemán y el Registro de la Propiedad español (art. 1,1. ${ }^{a}$ LH y art. 605 CC), que, llevados por una autoridad pública, ofrecían la publicidad de los derechos existentes sobre un determinado bien inmueble ${ }^{16}$. En los Registros se identifican las fincas y todas las mutaciones jurídico reales sufridas por las mismas, intentando así ofrecer en cada momento el estado jurídico vigente del inmueble ${ }^{17}$.

\section{Aspectos generales del derecho inmobiliario registral}

13. La normativa destinada al estudio del Registro de la Propiedad se encuentra dividida en una parte formal y otra material.

14. En su vertiente formal se establecen reglas procedimentales para asegurar el buen funcionamiento del Registro, fijando, por ejemplo, los requisitos para la redacción y extensión de un asiento y su publicidad formal, así como el modo de llevar el Registro ${ }^{18}$. En este aspecto, los regímenes casi no se distinguen. En Alemania se encuentra regulado en su mayor parte en la Grundbuchordnung ${ }^{19}$; y en España, en la Ley Hipotecaria y en el Reglamento Hipotecario ${ }^{20}$.

15. En cuanto a su vertiente material, los Ordenamientos español y alemán muestran algunas diferencias en el contenido de su derecho registral. En ambos sistemas, el conjunto de normas materiales conforma la base sobre la que se justifica y explica el valor de las inscripciones y de la protección registral $^{21}$. En Alemania, al ser la inscripción parte de la transmisión, el BGB, en sus $\S \S 873$ y ss., fija además los requisitos que han de ser cumplidos para provocar la mutación-jurídica ${ }^{22}$.

16. El tráfico de bienes inmuebles entraña un riesgo cuando quien adquiere no conoce la situación jurídico-real del bien, o cuando no puede estar seguro del poder de disposición del transmitente. Por ello, el Registro desempeña una función esencial para distintos tipos de derechos reales inmobiliarios y para distintos participantes en el tráfico jurídico ${ }^{23}$.

17. En primer lugar, es una fuente indispensable de información fácilmente accesible, sobre la que personas interesadas en la adquisición de un inmueble pueden adoptar su decisión de adquirir el mismo $^{24}$. La adquisición de un bien inmueble supone una inversión económica relevante por lo que la

\footnotetext{
${ }^{14}$ R. WeBER, Sachenrecht II - Grundstücksrecht, cit. § 4 apdo 6.

${ }^{15}$ L. J. Arrieta Sevilla, "La finca registral como objeto del registro de la propiedad", cit. pp. 29-48.

${ }^{16}$ M. Albaladejo, Derecho Civil III. Derecho de Bienes, cit. § 140.1; G. De Reina Tartière, Gabriel, "El Derecho registral inmobiliario y el Registro de la Propiedad", La Notaria, 2/2012, pp. 49 y 51;

R. Weber, Sachenrecht II - Grundstücksrecht, cit. § 4 apdo 2, 6; Wellenhofer, M., Sachenrecht, 32. Auflage, München 2017, cit. § 17 apdo 24.

17 J. Kuntze / R. Ertl / H. Herrmann / D. Eickmann, Grundbuchrecht: Kommentar Zu Grundbuchordnung Und Grundbuchverfügung Einschließlich Wohnungseigentumsgrundbuchverfügung, Sammlung Guttentag, German Edition, 1979 , A 7.

${ }^{18}$ F. J. Sánchez Calero / B. Sánchez Calero Arribas, Manual de derecho inmobiliario registral, 6 a Edición, Tirant lo Blanch, Valencia 2019, p. 26; K. VIEwEg / A. Werner, Sachenrecht, 7. Auflage, München 2015, cit. § 13 apdo 1.

${ }^{19}$ J. F. BAur/ R. StÜRner, Sachenrecht, cit. § 14 apdo 7.

${ }^{20}$ M. Albaladejo, Derecho Civil III. Derecho de Bienes, 10a Edición, Bosch, Barcelona 2004, cit. § 1412.

${ }^{21}$ F. J. SÁnchez Calero / B. SÁnchez Calero Arribas, Manual de derecho inmobiliario registral, cit. p. 26

22 J. F. BAUR/ R. STÜRner, Sachenrecht, cit. § 14 apdo 7; K. VIEWEg / A. Werner, Sachenrecht, cit., § 13 apdo 1.

${ }^{23}$ F. P. Méndez GonzÁlez, La función de la fe pública registral en la transmisión de bienes inmuebles - un estudio del sistema español con referencia al alemán, Tirant lo Blanch, Valencia, 2017, pp. 35 y ss.

${ }^{24}$ H. PRÜTtING, Sachenrecht, cit. § 15 apdo 132.
} 
necesidad de crear y mantener la seguridad jurídica aumenta considerablemente. Lo más valioso es el bien, lo más importante es poder averiguar con certeza quién es su dueño ${ }^{25}$.

18. En los países sin Registro de la Propiedad, los participantes del tráfico jurídico interesados en un determinado bien inmueble, tienen que practicar investigaciones previas extensas ${ }^{26}$. El Registro, sin embargo, facilita esa búsqueda y hace el tráfico más dinámico y menos arriesgado, al ofrecer información fiable y auténtica para comprobar la legitimación del transmitente y para conocer los gravámenes y cargas que recaen sobre la propiedad ${ }^{27}$. Permite, por lo tanto, ahorrar potenciales costes de investigación ${ }^{28}$.

19. Asimismo, a los titulares de una garantía real (por ejemplo de una hipoteca), le es de importancia poder consultar un medio que registra todas las garantías reales ya existentes ${ }^{29}$. Es el Registro de la Propiedad quien genera la posibilidad de gravar un inmueble con más de una carga, al asignar a cada una de ellas un determinado rango, según el cual será satisfecha ${ }^{30}$.

20. Un sistema registral necesita un aparato muy extenso de funcionarios que, sobre la base de normas procedimentales, vele por la integridad y exactitud de las inscripciones ${ }^{31}$. Por tanto, la gestión de un Registro de la Propiedad es costosa; pero, teniendo en cuenta los valores inmobiliarios y la relevancia de las garantías reales, se justifica por su utilidad práctica, tanto en sentido jurídico como económico ${ }^{32}$.

\section{Análisis comparado del Derecho alemán y español}

21. Antes de abordar la configuración de un Registro de la Propiedad Común Europeo es necesario analizar la situación legal actual, examinando los Registros de la Propiedad existentes en los distintos Estados miembros; sus principios básicos y cómo los implementan para asegurar el correcto funcionamiento registral. A modo de ejemplo, los siguientes epígrafes se dedicarán al estudio comparado de los sistemas registrales alemán y español. En la primera parte, se tratará el "derecho registral formal", estudiando la organización y estructura, así como la publicidad formal de los dos Registros. Después, pasando al "derecho registral material", se analizarán los asientos de inscripción: ¿qué requieren?, ¿qué valor tienen? y ¿qué consecuencias jurídicas están conectadas a su práctica? Y, con especial atención, los conceptos de fe pública en ambos.

22. El derecho registral está construido sobre la base del derecho real material, con lo cual éste puede explicar y justificar algunos de los principios fundamentales que caracterizan los sistemas registrales ${ }^{33}$. En la primera parte se llevará a cabo una comparativa del derecho real material de ambos Ordenamientos civiles.

\footnotetext{
${ }^{25}$ H. Prütting, Sachenrecht, cit. § 15 apdo 131.

${ }^{26}$ J. L. Lacruz Berdejo / J. Delgado Echeverría / J. J. Rams Albesa, Elementos de Derecho Civil. III bis, Derecho inmobiliario registral, cit. p. 23.

${ }^{27}$ A. Gordillo CAÑAS, "La peculiaridad de nuestro sistema hipotecario frente a los modelos latino y germánico: la publicidad registral como apariencia jurídica", Anuario de Derecho Civil, Vol. 47, № 2, 1994, pp. 31 y 42; J. L. LACRUz BERDEJo / J. Delgado Echeverría / J. J. Rams Albesa, Elementos de Derecho Civil. III bis, Derecho inmobiliario registral, cit. p. 23 ; H. PRÜTTING, Sachenrecht, cit. § 15 apdos 132 y s.

${ }^{28}$ F. P. MÉndez GonzÁlez, La función de la fe pública registral en la transmisión de bienes inmuebles - un estudio del sistema español con referencia al alemán, cit., p. 61.

${ }^{29}$ H. PrütTING, Sachenrecht, cit. § 15 apdo 136.

${ }^{30}$ H. PRÜTting, Sachenrecht, cit. § 15 apdos 132 y 136.

${ }^{31}$ J. Holzer / A. Kramer, Grundbuchrecht, 2. Auflage, München, 2004, apdo 6; H. PrÜtTING, Sachenrecht, cit. § 15 apdo 132; Wellenhofer, M., Sachenrecht, cit. § 17 apdo 31.

32 J. Holzer / A. Kramer, Grundbuchrecht, cit. apdos 1 y 6; H. Wilsch, Grundbuchordnung für Anfänger, 2. Auflage, München, 2017, apdo 11; H. PrÜTTING, Sachenrecht, cit. § 15 apdo 132.

${ }_{33}$ J. F. BAUR/ R. STÜRNER, Sachenrecht, cit. § 14 apdo 8.
} 


\section{Régimen de transmisión de los derechos reales}

\section{A) En Alemania: principio de separación y abstracción. Acuerdo e inscripción}

23. Conforme al "principio de separación" que domina todo el Ordenamiento civil alemán, el negocio jurídico obligacional y el negocio jurídico real deben en todo caso ser separados ${ }^{34}$. Esto significa que, por un lado, el adquirente y el transmitente celebran un contrato que se limita a provocar efectos vinculantes, y por otro, hay transmisión del bien y, en su caso, transmisión del dinero.

24. De acuerdo con el "principio de abstracción", la mutación jurídico-real está desconectada de una causa y se basa únicamente en el acuerdo real y la transmisión del bien ${ }^{35}$. Los dos negocios son independientes uno del otro tanto en su origen como en su existencia, así que la nulidad del negocio jurídico obligacional no afecta a la eficacia de la mutación jurídico-real ${ }^{36}$.

25. El $\S 873$ BGB es la norma fundamental en la regulación de las disposiciones sobre un bien inmueble ${ }^{37}$, dado que fija los dos requisitos necesarios para transmitir o adquirir un derecho relacionado con un bien inmueble: el acuerdo y la inscripción. Según percepción general, estos elementos son tanto independientes como equivalentes en su trascendencia jurídica al provocar la modificación jurídico-real ${ }^{38}$.

26. La citada norma refleja el concepto básico para transmitir un derecho real, regulado en el $\S 929$ BGB, trasladándolo al ámbito de los bienes inmuebles ${ }^{39}$. En principio el $\S 873$ recoge el mismo concepto que el $\S 929 \mathrm{BGB}$, pero $\S 929$ es la norma general que se refiere a la transmisión de cualquier derecho real mientras que $\S 873$ se refiere explícitamente al ámbito de los bienes inmuebles; o sea $\S 929$ requiere acuerdo y entrega; y el $\S 873$ requiere acuerdo e inscripción.

27. Las partes han de llegar a un acuerdo real, expresando el transmitente su voluntad de enajenar y el adquirente su voluntad de adquirir el derecho real ${ }^{40}$. Debido al "principio de separación" que, como ya se ha indicado, caracteriza al Derecho civil alemán, el "acuerdo", en el sentido del § 873 BGB es ajeno a éste, al que las partes llegan cuando celebran el negocio jurídico constitutivo de la obligación, y se refiere por tanto exclusivamente a la producción de la modificación jurídico-real ${ }^{41}$. Tampoco equivale al consentimiento de inscripción del $\S 29$ GBO, que las partes han de prestar ante la autoridad competente que lleva el Registro -aunque pueden ser efectuados simultáneamente- sino que representa un contrato real autónomo que va dirigido al cambio jurídico-real ${ }^{42}$.

28. Únicamente en la transmisión de la propiedad de un inmueble, se requiere una determinada formalización del acuerdo (“Auflassung”, § $925 \mathrm{BGB})^{43}$. En los demás supuestos, rige la libertad de forma.

29. La transmisión no se efectúa con la sola voluntad de las partes sino que requiere la coincidente inscripción en el Grundbuch; "coincidente" porque el contenido de la inscripción ha de ser congruente

\footnotetext{
${ }^{34}$ Wellenhofer, M., Sachenrecht, cit. § 17 apdo 1; J. F. Baur/ R. Stürner, Sachenrecht, 18, cit. § 5 apdo 40.

${ }^{35}$ A. Gordillo CaÑas, "La inscripción en el Registro de la Propiedad (Su contenido causal, su carácter voluntario y su función publicadora de la realidad jurídico-inmobiliaria o generadora de su apariencia jurídica)", Anuario de Derecho Civil, Vol. 54, $\mathrm{N}^{\circ} 1,2001$, p. 28.

${ }^{36}$ J. F. BAUR/ R. STÜRNER, Sachenrecht, cit. § 5 apdo 41.

${ }^{37}$ Münchener Kommentar zum Bürgerlichen Gesetzbuch, cit. § 873 apdo 1.

${ }^{38}$ Wellenhofer, M., Sachenrecht, cit. § 17 apdo 12.

${ }^{39}$ Münchener Kommentar zum Bürgerlichen Gesetzbuch, cit. § 873 apdo 2.

40 J. F. BAUR/ R. STÜRNER, Sachenrecht, cit. § 19 apdo 9.

${ }^{41}$ Münchener Kommentar zum Bürgerlichen Gesetzbuch, cit. $\S 873$ apdos 3 y 50; H. P. Westermann / A. Staudinger, $B G B$-Sachenrecht, 13. Auflage, München, 2017, apdo 362.

${ }^{42}$ O. Palandt, Bürgerliches Gesetzbuch, Kommentar, 79. Auflage, München 2020, § 873 apdo 9.

${ }^{43}$ Wellenhofer, M., Sachenrecht, cit. § 17 apdo 13.
} 
con el contenido del acuerdo ${ }^{44}$. Aunque el acuerdo de las partes en sí, de conformidad con el $\S 873$ II BGB, es obligatorio, no produce efectos jurídico-reales sin la práctica de la inscripción ${ }^{45}$. La inscripción es el elemento que da publicidad a la mutación jurídico-real, haciéndola cognoscible para terceros ${ }^{46}$.

\section{B) En España: teoría del título y el modo}

30. En el Derecho español, la transmisión de cosas corporales, la adquisición derivativa de éstas sigue el sistema tradicional del título y el modo, que, teniendo su raíz en el Derecho Romano, está regulado en el art. $609 \mathrm{CC}^{47}$. El art. $1095 \mathrm{CC}$ complementa el citado precepto al establecer que el acreedor "no adquirirá derecho real sobre ella [la cosa] hasta que le haya sido entregada"48.

31. En este sentido, el "título" es el contrato antecedente por el cual las partes consienten la transmisión de una cosa, que, siempre que sea existente y válido, representa la justa causa para la transmisión ${ }^{49}$. Es un negocio jurídico causal que, por sí solo, genera un derecho de crédito, sin que su conclusión baste para producir la adquisición ${ }^{50}$. Si este negocio precedente es, por ejemplo, un contrato de compraventa, el vendedor, tal como indica el art. $1145 \mathrm{CC}$, se obliga a entregar la cosa vendida al comprador y el adquirente a aportar la contraprestación.

32. Puesto que el pacto en sí no tiene efectos jurídico-reales, no es suficiente para concluir la transmisión, sino que requiere adicionalmente la ejecución del modo, es decir, la tradición de la cosa transmitida ${ }^{51}$. Este acto, el "modo", es el segundo requisito de la transmisión. La tradición está compuesta por dos aspectos: el corpus y el animus. Significa que, además de la entrega real, las partes deben estar de acuerdo sobre la misma y expresar su intención o voluntad de transferir y de aceptar la transferencia respectivamente ${ }^{52}$.

33. El modo originario de "tradición real" consiste en la entrega o traspaso de la cosa y la consiguiente toma en poder y posesión por parte del adquirente, con ánimo de transmitir y adquirir el dominio, cumpliendo así su función de ser "signo de recognoscibilidad"53. Alternativamente, los bienes inmuebles pueden ser transmitidos por la entrega de llaves (art. 1463 CC), siendo la tradición simbólica, o a través de la "tradición instrumental", prevista en el art. 1462 II CC, al que remite el art. 1464 CC $^{54}$. Establece dicho precepto que cuando se formaliza la compraventa en escritura pública, el otorgamiento de ésta equivaldrá a la entrega de la cosa, salvo que se estableciese lo contrario ${ }^{55}$.

\footnotetext{
${ }^{44}$ Wellenhofer, M., Sachenrecht, cit. § 17 apdo 21.

${ }^{45}$ Münchener Kommentar zum Bürgerlichen Gesetzbuch, cit. § 873 apdo 93.

${ }^{46}$ H. P. Westermann / A. Staudinger, BGB-Sachenrecht, cit. apdo 362.

${ }^{47}$ J. R. Verda y Beamonte / A. Serra Rodríguez / M. L. Atienza Navarro, Derecho civil III (Derechos reales), cit. p. 56; B. LöBER, Grundeigentum in Spanien - Handbuch für Eigentümer, Käufer und Verkäufer, 4. Auflage, Frankfurt a.M., 1993, p. 26.

${ }^{48}$ C. Frankenheim, Das deutsche Grundbuch und das spanische Eigentumsregister - eine rechtsvergleichende Untersuchung, Frankfurt a.M, 1985, p. 63.

${ }^{49}$ C. Frankenheim, Das deutsche Grundbuch und das spanische Eigentumsregister - eine rechtsvergleichende Untersuchung, cit. p. 62.

${ }^{50}$ M. Albaladejo, Derecho Civil III. Derecho de Bienes, cit. $§ 22$ 1; J. R. Verda y Beamonte / A. Serra Rodríguez / M. L. Atienza Navarro, Derecho civil III (Derechos reales), cit. p. 56.

${ }^{51}$ J. R. Verda y Beamonte / A. Serra Rodríguez / M. L. Atienza Navarro, Derecho civil III (Derechos reales), cit. p. 56.

${ }^{52}$ M. Albaladejo, Derecho Civil III. Derecho de Bienes, cit. $\$ 221$.

${ }^{53}$ J. R. Verda y Beamonte / A. Serra Rodríguez / M. L. Atienza Navarro, Derecho civil III (Derechos reales), cit. p. 58; J. SÁnchez Cebrián, "La teoría general de la transmisión de bienes y el registro de la propiedad en España", Revista de Derecho: División de Ciencias Jurídicas de la Universidad del Norte, $\mathrm{N}^{\circ} 30$, Barranquilla, 2008, p. 13.

${ }^{54}$ J. R. Verda y Beamonte / A. Serra Rodríguez / M. L. Atienza Navarro, Derecho civil III (Derechos reales), cit. p. 59.

${ }^{55}$ B. LÖBER, Grundeigentum in Spanien - Handbuch für Eigentümer, Käufer und Verkäufer, 4. Auflage, Frankfurt a.M., 1993, p. 26.
} 
34. Por consiguiente, un bien inmueble puede ser transmitido por la formalización en escritura pública del contrato de compraventa, siendo el contrato formalizado el título y el otorgamiento de la escritura pública el modo previsto por el art. 1462 II CC $^{56}$.

\section{C). Resultado de la comparación del derecho material}

35. En el Derecho español la tradición, que está configurada como una figura causal, se legitima en la existencia de una causa, o sea, de una razón de ser. Por ello, el antes mencionado título es imprescindible para operar la transferencia. Al ser así, el sistema español se diferencia fundamentalmente del sistema alemán en el sentido de que en este último la esfera obligatoria y la real están estrictamente separadas y desconectadas ${ }^{57}$.

\section{Aspectos Formales del Registro de la Propiedad}

\section{A) Organización y estructura en Alemania y España}

36. En Europa existen dos sistemas históricos distintos de organización formal del Registro. E1 sistema del folio real, de tradición germánica, y el sistema personal, de origen romano ${ }^{58}$.

37. El Grundbuch es el modelo del Derecho germánico y se organiza sobre la base del folio real ${ }^{59}$. Esto significa que cada finca tiene su propio folio en el cual se publican todos los derechos relacionados con la misma ( $\$ 3 \mathrm{GBO}$ ), tales como: la titularidad, posibles cargas y gravámenes, servidumbres, etc ${ }^{60}$. El "folio", compuesto por doce páginas, está encabezado por los datos relativos a la identificación del inmueble y luego dividido en tres secciones. La primera se dedica a las relaciones de propiedad, el derecho real más fuerte ${ }^{61}$, la segunda a cargas y limitaciones, y la última a hipotecas y gravámenes pecuniarios semejantes $^{62}$. Todos los derechos se registran por orden cronológico ${ }^{63}$. Al seguir siendo visibles y constatables los derechos eliminados, el folio real crea un historial de la finca. El folio refleja el estado actual de cada inmueble y permite, por lo tanto, extraer fácilmente toda la información jurídica relevante ${ }^{64}$.

38. En España el Registro de la Propiedad es llevado en dos libros: el de Inscripciones, que es el verdadero Registro, y el Diario, en el cual se practican los asientos de presentación ${ }^{65}$. El sistema español, que integra elementos tanto del sistema romano como del sistema germánico $0^{66}$, opta también por la organización por fincas, el sistema del folio real (art. 9 LH). Las fincas son objetos duraderos, fijos, naturalmente visibles y tangibles, de manera que presentan un buen eje en torno al cual gira la institución registral ${ }^{67}$.

${ }^{56}$ F. J. Sánchez Calero / B. Moreno Quesada, Curso de Derecho Civil III, Derechos reales y registral inmobiliario, $8^{\mathrm{a}}$ Edición, Tirant lo Blanch, Valencia 2019, p. 48.

${ }^{57}$ F. J. Sánchez Calero / B. Moreno Quesada, Curso de Derecho Civil III, Derechos reales y registral inmobiliario, cit. p. 46.

${ }^{58}$ C. S. Rupp, "Germanisches Grundbuch und romanisches Register: Harmonisierende Überlegungen”, cit. pp. 567 y 571.

${ }^{59}$ A. Manzano Solano, "Las instituciones registrales en los países occidentales", en Díaz Fraile (coord.), Estudios de Derecho Europeo Privado, Centro de Estudios Registrales, Madrid, 1994, p. 586.

${ }^{60}$ J. Kuntze / R. Ertl / H. Herrmann / D. Eickmann, Grundbuchrecht: Kommentar Zu Grundbuchordnung Und Grundbuchverfügung Einschließlich Wohnungseigentumsgrundbuchverfügung, cit. § 3, apdo 2.

${ }^{61}$ H. WILSCH, Grundbuchordnung für Anfänger, cit. apdo 66.

${ }^{62}$ J. L. Lacruz Berdejo / J. Delgado Echeverría / J. J. Rams Albesa, Elementos de Derecho Civil. III bis, Derecho inmobiliario registral, cit. p. 18.

${ }^{63}$ H. WILSCH, Grundbuchordnung für Anfänger, cit. apdo 66.

${ }^{64}$ C. S. Rupp, “Germanisches Grundbuch und romanisches Register: Harmonisierende Überlegungen”, cit. pp. 567 y 571.

${ }^{65}$ M. Albaladejo, Derecho Civil III. Derecho de Bienes, cit. § 1414.

${ }^{66}$ A. Manzano Solano, "Las instituciones registrales en los países occidentales", en Díaz Fraile (coord.), Estudios de Derecho Europeo Privado, cit. p. 611.

${ }^{67}$ F. J. Sánchez Calero / B. Sánchez Calero Arribas, Manual de derecho inmobiliario registral, $6^{a}$ Edición, Tirant lo Blanch, Valencia 2019, p. 38. 
Cada finca se inscribe en un folio aparte y con un número especial y correlativo (art. $8 \mathrm{LH})^{68}$. El primer ingreso de una finca al Registro requiere su inmatriculación, en virtud de la cual se identifica la finca por sus características de hecho, la descripción física y geográfica del inmueble ${ }^{69}$. Todos los títulos que alteran los derechos inmobiliarios o las titularidades de los mismos, se inscriben sucesivamente con número consecutivo en la única sección del folio (art. $243 \mathrm{LH})^{70}$. La continuidad proviene siempre del último título inscrito, pudiendo, quien consulte el Registro para conocer la situación de un inmueble, guiarse por el historial de los asientos de inscripción practicados en el folio ${ }^{71}$.

\section{B) Requisitos formales de la inscripción en Alemania y España}

39. En Alemania existen varios requisitos para que la oficina del Registro proceda a la inscripción. En primer lugar, una de las partes del negocio jurídico, el transmitente o el adquirente, tiene que solicitar la inscripción $(\S 13 \mathrm{GBO})^{72}$. De acuerdo con el $\S 19 \mathrm{GBO}$, el transmitente o disponente tiene que prestar su autorización con la inscripción ante la oficina ${ }^{73}$. Esta autorización no equivale a la declaración de voluntad en el acuerdo real. Finalmente, en atención al "principio de inscripción previa", fijado en el $\S 39 \mathrm{GBO}$, es imprescindible que quien pretenda transmitir su derecho sea titular registral y esté así legitimado para realizar la disposición ${ }^{74}$. En base al "principio de legalidad", el Registrador de la Propiedad comprobará la presencia de los requisitos de los $\S 19,20,29$ GBO, para que el Registro no contengan incorrecciones. No obstante, su poder de control se limita a errores evidentes ${ }^{75}$.

40. En España, conforme al "principio de rogación”, el Registro de la Propiedad solo practica el asiento de inscripción a petición de una persona legitimada. El art. 6 LH establece que puede ser a instancia de las partes o de otra persona interesada en la publicidad del derecho. La petición debe estar acompañada por la presentación del título, cuyo ingreso al Registro se pretende y debe constar en documento público $^{76}$. Aparte de ello, si el acto trata de disponer de un derecho, es necesario que el transmitente conste en el Registro como titular del mismo ${ }^{77}$. Es el llamado "principio del tracto sucesivo" regulado en el art. 20.1 y $2 \mathrm{LH}^{78}$. Recibida una petición, el Registrador debe primero extender un asiento de presentación en el libro Diario, señalando el momento de la misma (día y hora). A la luz del "principio de prioridad" del art. $24 \mathrm{LH}$, el primero en presentar será el primero inscrito ${ }^{79}$. Además, a raíz del "principio de legalidad", solamente deben acceder al Registro los documentos que la ley permite ${ }^{80}$. Durante un plazo fijado legalmente, el Registrador debe comprobar el cumplimiento de los requisitos, comunicar al solicitante los posibles errores subsanables, y, en su caso, realizar el asiento solicitado en el libro de Inscripciones ${ }^{81}$.

\footnotetext{
${ }^{68}$ F. J. SÁnchez Calero / B. SÁnchez Calero Arribas, Manual de derecho inmobiliario registral, cit. p. 39.

${ }^{69}$ M. Albaladejo, Derecho Civil III. Derecho de Bienes, cit. § 143 2; J. L. Lacruz Berdejo / J. Delgado Echeverría / J. J. Rams Albesa, Elementos de Derecho Civil. III bis, Derecho inmobiliario registral, cit. p. 58.

${ }^{70}$ M. Albaladejo, Derecho Civil III. Derecho de Bienes, cit. § 141 5; J. L. Lacruz Berdejo / J. Delgado Echeverría / J. J. Rams Albesa, Elementos de Derecho Civil. III bis, Derecho inmobiliario registral, cit. p. 57; F. J. SÁnchez Calero / B. SÁnCheZ CAlero Arribas, Manual de derecho inmobiliario registral, cit. p. 38.

71 M. Albaladejo, Derecho Civil III. Derecho de Bienes, cit. § 146 1; J. L. Lacruz Berdejo / J. Delgado Echeverría / J. J. Rams Albesa, Elementos de Derecho Civil. III bis, Derecho inmobiliario registral, cit. p. 58; B. LöBer, Grundeigentum in Spanien - Handbuch für Eigentümer, Käufer und Verkäufer, cit., p. 41.

${ }^{72}$ Wellenhofer, M., Sachenrecht, cit. § 17 ap. 35.

${ }^{73}$ Wellenhofer, M., Sachenrecht, cit. § 17 ap. 36.

${ }^{74}$ Wellenhofer, M., Sachenrecht, cit. § 17 ap. 39.

${ }^{75}$ BayObLG NJW-RR 1989, 910.

${ }^{76}$ M. Albaladejo, Derecho Civil III. Derecho de Bienes, cit. § 1452 y §149 1.

${ }^{77}$ M. AlbaladeJo, Derecho Civil III. Derecho de Bienes, cit. § 1452.

${ }^{78}$ G. De Reina Tartière, Gabriel, "El Derecho registral inmobiliario y el Registro de la Propiedad”, cit., pp. 49, 58.

${ }^{79}$ M. Albaladejo, Derecho Civil III. Derecho de Bienes, cit. § 149 2; B. LöBer, Grundeigentum in Spanien - Handbuch für Eigentümer, Käufer und Verkäufer, cit. p. 42.

${ }^{80}$ M. Albaladejo, Derecho Civil III. Derecho de Bienes, cit. § 1493.

${ }^{81}$ M. Albaladejo, Derecho Civil III. Derecho de Bienes, cit. § 149 3; B. LöBer, Grundeigentum in Spanien - Handbuch für Eigentümer, Käufer und Verkäufer, cit. p. 42.
} 


\section{C) Publicidad Formal en Alemania y España}

41. La publicidad formal, que se refiere a la accesibilidad de la información a las personas interesadas en el tráfico jurídico, es un elemento clave para que el Registro pueda cumplir con su finalidad de publicidad material ${ }^{82}$.

42. Existe una relación recíproca estrecha entre este aspecto del derecho registral formal y el derecho registral material, dado que sin la posibilidad de consultar y conocer los asientos registrales no hay fe pública registral y, al revés, no hay fe pública sin posibilidad de conocimiento ${ }^{83}$. Esto muestra que las decisiones legislativas adoptadas en el marco de la configuración del derecho registral material han de encontrar su reflejo en el derecho registral formal ${ }^{84}$.

43. En Alemania el art. 12 GBO establece la posibilidad de consultar el Grundbuch para llegar a conocer el estado jurídico de un bien inmueble ${ }^{85}$. El Grundbuch es el medio que proporciona fiablemente toda la información relevante ${ }^{86}$. Aun así, no se trata de una publicidad formal absoluta, tal como ocurre en el Registro Mercantil, sino que se limita el derecho a consultar a las personas que demuestren tener un interés legítimo en tal conocimiento ${ }^{87}$. La restricción busca evitar consultas excesivas e innecesarias y, además, proteger los intereses de discreción respecto a la situación económica y a los datos personales de las personas inscritas ${ }^{88}$. El funcionario de la oficina registral es quien decidirá sobre la legitimidad del interés reclamado, pudiendo este ser tanto de naturaleza jurídico-privada, económica, real, pública o incluso científica ${ }^{89}$. Aunque la restricción pretende, entre otras cosas, proteger el interés de discreción de las personas inscritas, ellas quedan al margen del proceso de decisión ${ }^{90}$.

44. Los legitimados para consultar el Grundbuch están igualmente legitimados para solicitar una copia simple o una copia certificada que refleje el contenido exacto del mismo ${ }^{91}$. Mientras que una inexactitud en la copia simple no trae consigo ninguna consecuencia, los errores en la copia certificada pueden desencadenar una responsabilidad de resarcimiento del Estado ${ }^{92}$.

45. Por su parte, en España, el art. 221 LH aclara que "los registros serán públicos". Sin embargo, debido a la protección de los datos de carácter personal y del derecho a la intimidad, al igual que en el derecho alemán, para poder consultar el Registro, el solicitante debe acreditar tener un interés legítimo ${ }^{93}$. Para acreditar tal interés, se requiere que el conocimiento que pretende sea de alguna importancia patrimonial para el solicitante, como lo es, por ejemplo, pretender adquirir un derecho real ${ }^{94}$. El Registrador será quien decida si el motivo expresado es de carácter patrimonial y si, consiguientemente, es conforme a la finalidad del Registro ${ }^{95}$.

${ }^{82}$ F. J. Sánchez Calero / B. Sánchez Calero Arribas, Manual de derecho inmobiliario registral, cit. p. 221; L. J. Arrieta SeviLla, "La finca registral como objeto del registro de la propiedad", cit. 29-48.

${ }^{83}$ H. WILSCH, Grundbuchordnung für Anfänger, cit. apdo 39.

${ }^{84} \mathrm{H}$. WILSCH, Grundbuchordnung für Anfänger, cit. apdo 40.

${ }^{85}$ H. P. Westermann / K. H. Gursky / D. Eickmann, Sachenrecht, 8. Auflage, Heidelberg, 2011, § 67 apdo 21.

${ }^{86}$ C. FranKenheim, Das deutsche Grundbuch und das spanische Eigentumsregister - eine rechtsvergleichende Untersuchung, cit. p. 19.

${ }^{87} \mathrm{H}$. WILSCH, Grundbuchordnung für Anfänger, cit. apdo 40.

${ }^{88}$ Wellenhofer, M., Sachenrecht, cit. § 17 apdo 29; K. VIeWEg / A. Werner, Sachenrecht, cit. § 13 apdo 8.

${ }^{89}$ Wellenhofer, M., Sachenrecht, cit. § 17 apdos 29 y ss.; K. Vieweg / A. Werner, Sachenrecht, cit. § 13 apdo 8.

${ }^{90} \mathrm{H}$. WiLsch, Grundbuchordnung für Anfänger, cit. apdo. 43.

${ }^{91}$ H. SCHÖNER / K. STÖBER, Grundbuchrecht - Handbuch der Rechtspraxis, Band 4, 15. Auflage, München, 2012, apdos 535 y ss.

92 J. Demharter, Grundbuchordnung, 31, Auflage, München 2018, § 12 apdos 25 y 29.

${ }^{93}$ C. FrankenheIm, Das deutsche Grundbuch und das spanische Eigentumsregister - eine rechtsvergleichende Untersuchung, cit. p. 91.

${ }^{94}$ F. J. Sánchez Calero / B. Sánchez Calero Arribas, Manual de derecho inmobiliario registral, cit. p. 222.

${ }^{95}$ C. Frankenheim, Das deutsche Grundbuch und das spanische Eigentumsregister - eine rechtsvergleichende Untersuchung, cit. p. 91. 
46. Para quienes demuestren tener un interés legítimo, lícito y patrimonial, el Derecho registral ha de prever medios a través de los cuales éstos puedan llegar a conocer el contenido de los asientos ${ }^{96}$. El art. 222.1 LH regula la exhibición de los libros, es decir la inspección del Registro en la parte necesaria sin salir los libros de la oficina. La nota simple informativa, regulada en el art. $222.5 \mathrm{LH}$, debe reflejar fielmente los datos relevantes contenidos en el Registro, correspondiendo a una reproducción literal o a un extracto del contenido. Tiene valor solo informativo y carece de calidad jurídica (art. $332 \mathrm{RH})^{97}$. Otra posibilidad es la certificación, prevista en los arts. 223 y ss. LH, consistente en un traslado del contenido del Registro confeccionado por el Registrador bajo fe. La certificación es un documento público y el único medio con el cual el interesado puede acreditar la presencia o ausencia de gravámenes en los inmuebles ${ }^{98}$.

\section{Derecho inmobiliario material en Alemania}

\section{A) Valor y efectos de la inscripción}

47. De conformidad con los $\S \S 873$ y 875 BGB la inscripción en el Grundbuch es requisito para la generación de una mutación de orden jurídico-negocial ${ }^{99}$. Sin embargo, la inscripción por sí tampoco es suficiente para provocar la modificación ${ }^{100}$. En vez de ello, aunque por regla general no ha de ser acreditado ante el Registrador de la Propiedad, se requiere la existencia del acuerdo real, cuyo contenido sea coincidente en todos aspectos con el contenido de la inscripción ${ }^{101}$.

48. El orden cronológico no tiene relevancia, solo cuenta que a partir de algún momento, ambos requisitos concurran simultáneamente ${ }^{102}$. Al formar parte siempre del proceso de transmisión y ser necesario para provocar la consecuencia jurídica deseada, la inscripción registral tiene un valor constitutivo para la mutación jurídico-real ${ }^{103}$. Es el acto de perfeccionamiento que concluye la adquisición del derecho $^{104}$. El Derecho registral alemán impone el principio de la inscripción constitutiva ${ }^{105}$.

49. De lo anterior se desprende que el Grundbuch desempeña una función esencial en cualquier cambio jurídico-real: sea una transmisión, un gravamen o la modificación o eliminación de un derecho ( $\S 873,875,877$ BGB). La inscripción en el Grundbuch es hecho generador.

50. Al mismo tiempo, constituye la publicidad para que la mutación jurídico-real sea cognoscible externamente ${ }^{106}$. La inscripción sustituye, por ende, la tradición, que se lleva a cabo en el derecho mobiliario, según $\S 929$ BGB $^{107}$.

51. Considerando la necesidad innegociable de la inscripción, resulta claro que ésta no se deja a la autonomía de las partes, sino que es en todo caso obligatoria. Si se omite la práctica de la inscripción, el derecho no nace.

${ }^{96}$ M. Albaladejo, Derecho Civil III. Derecho de Bienes, cit. § 152; F. J. Sánchez Calero / B. Sánchez Calero Arribas, Manual de derecho inmobiliario registral, cit. p. 221.

${ }^{97}$ Frankenheim, Das deutsche Grundbuch und das spanische Eigentumsregister - eine rechtsvergleichende Untersuchung, cit. p. 93; F. J. SÁnchez Calero / B. SÁnchez Calero Arribas, Manual de derecho inmobiliario registral, cit. p. 224.

${ }^{98}$ M. Albaladejo, Derecho Civil III. Derecho de Bienes, cit. § 152.

${ }^{99}$ R. LemKe, Kommentar Immobilienrecht, 2. Auflage, Köln, 2016, § 873 BGB apdos 1 y 17.

${ }^{100}$ J. Demharter, Grundbuchordnung, cit. § 13 apdo 10.

${ }^{101}$ Wellenhofer, M., Sachenrecht, cit. § 17 apdo 21.

102 J. DemHARTER, Grundbuchordnung, cit. § 13 apdo 11.

${ }^{103}$ J. Holzer / A. KRAmer, Grundbuchrecht, cit. apdo 101.

${ }^{104}$ H. WILSCH, Grundbuchordnung für Anfänger, cit. apdo 12.

105 A. Manzano Solano, "Las instituciones registrales en los países occidentales", cit. p. 591.

${ }^{106}$ H. Kollhosser, "Das Grundbuch - Funktion, Aufbau, Inhalt”, Juristische Ausbildung, 1984, pp. 558; J. KunTZE / R. ERTL / H. Herrmann / D. Eickmann, GrundBuchrecht: Kommentar Zu Grundbuchordnung Und Grundbuchverfügung Einschließlich Wohnungseigentumsgrundbuchverfügung, cit. A 11; K. Vieweg / A. Werner, Sachenrecht, cit. § 13 apdo 38; H. P. WestermanN / A. STAUDINGER, BGB-Sachenrecht, cit. apdo 362.

${ }^{107}$ H. P. Westermann / A. STAUdinger, BGB-Sachenrecht, cit. apdo 362. 
52. Sin perjuicio de lo anteriormente indicado, el BGB establece algunas excepciones a la inscripción constitutiva ${ }^{108}$. En ciertos supuestos se otorga prioridad a la causa que origina la mutación jurídico-real sobre el principio de la inscripción constitutiva, provocándose la disposición fuera del Grundbuch ${ }^{109}$. Ejemplos de ellos, son la sucesión universal o la adjudicación del bien por subasta. Como resultado de la disposición extra-registral, el contenido del Registro es inexacto al no reflejar el derecho inmediatamente en el momento de su nacimiento ${ }^{110}$. El legislador, en vez de obligar al adquirente, introduce elementos legales beneficiosos que motivarán la inscripción posterior de los cambios, pretendiendo con ello recuperar la exactitud registral para que refleje en todo momento la situación de propiedad real y guarde el principio de publicidad.

53. La mayor razón para proceder a la inscripción lo antes posible es el riesgo de la pérdida del derecho, que emana de la posible adquisición por un tercero de buena fe mientras que el titular legítimo no esté inscrito en dicho Registro ${ }^{111}$. A su vez, encontramos otros preceptos legales que promueven la inscripción igualmente; entre ellos, los $\S \S 19,39$ I GBO, que establecen la necesidad imperiosa de estar inscrito como titular legítimo en el Registro para poder disponer sobre el derecho ${ }^{112}$.

\section{B) Fe pública registral}

54. El Grundbuch no se limita a registrar los derechos ${ }^{113}$. Su contenido crea una apariencia jurídica convirtiendo al Registro en un soporte de fe pública, al intervenir el Estado en la inscripción de derechos ${ }^{114}$. Se podría argumentar que la garantía de exactitud del Registro nace ya gracias al efecto constitutivo de la inscripción ${ }^{115}$. No obstante, como ya se ha indicado, hay casos que provocan una inexactitud del Registro, por lo menos temporal, cuando la mutación jurídico-real se genera fuera del mismo. Aparte de esto, tampoco puede excluirse que puedan surgir ciertos errores en el negocio jurídico o simplemente en la práctica de la inscripción, que igualmente pueden traer consigo una inexactitud registral ${ }^{116}$. Pese al alto grado de coherencia entre la situación registral y la situación real característico del sistema registral alemán, no es posible garantizar en todo momento la exactitud de un asiento. Son estas situaciones de discordancia las que exigen del Registro ir más allá de ser un medio meramente informativo para el tráfico jurídico, al complementarse por la fe pública registral ${ }^{117}$.

55. La presunción de exactitud del $\S 891$ BGB. Uno de los efectos que deriva del principio de la fe pública registral es la presunción de exactitud ${ }^{118}$. Salvo en el caso de que el asiento fuera nulo, se presume que un derecho inscrito existe, según el $\S 891$ I BGB, y que un derecho eliminado ya no existe, según el $\S 891$ II BGB $^{119}$. La presunción opera tanto para el Registrador de la Propiedad como para los participantes del tráfico jurídico ${ }^{120}$.

56. Sin embargo, el $\S 891$ BGB es una norma de trascendencia solamente procesal ${ }^{121}$. Impone la carga de la prueba a la parte que pretenda derivar derechos de tal inexactitud, y gana por lo tanto es-

\footnotetext{
${ }^{108}$ K. VIEWEG / A. WERnER, Sachenrecht, cit. § 13 apdo 15.

${ }^{109}$ C. S. RuPP, “Germanisches Grundbuch und romanisches Register: Harmonisierende Überlegungen”, cit. pp. 567 y 578.

${ }^{110}$ J. F. BAUR/ R. STÜRNER, Sachenrecht, cit. $§ 18$ apdo 4.

${ }^{111}$ C. S. Rupp, "Germanisches Grundbuch und romanisches Register: Harmonisierende Überlegungen”, cit. pp. 567 y 578.

${ }^{112}$ C. S. RupP, “Germanisches Grundbuch und romanisches Register: Harmonisierende Überlegungen”, cit. pp. 567 y 579.

${ }_{113}$ J. F. BAUR/ R. STÜRNER, Sachenrecht, cit. § 23 I.

${ }^{114}$ K. VIEWEG / A. WeRnER, Sachenrecht, cit. $\S 13$ apdo 38.

${ }^{115}$ R. Weber, Sachenrecht II - Grundstücksrecht, 4. Auflage, Baden-Baden 2015, § 4 apdo 15.

${ }^{116}$ R. WeBER, Sachenrecht II - Grundstücksrecht, cit. § 4 apdo 15.

117 J. F. BAUR/ R. STÜRnER, Sachenrecht, cit. § 23 I.

${ }^{118}$ R. WeBER, Sachenrecht II - Grundstücksrecht, cit. § 4 apdo 11, § 8 apdo 7; J. F. BAUR/ R. STÜRNER, Sachenrecht, cit. §

119 J. Demharter, Grundbuchordnung, cit. § 13 apdo 15; Wilsch, GBO, apdo 13.

${ }^{120} \mathrm{H}$. WILSCH, Grundbuchordnung für Anfänger, cit. apdo 13.

${ }^{121}$ R. WEBER, Sachenrecht II - Grundstücksrecht, cit. § 8 apdo 7.
} 23 apdo 1. 
pecial importancia cuando es imposible clarificar la situación jurídico-real ${ }^{122}$. Al permitir la prueba en contrario, el $\S 891$ BGB establece una presunción iuris tantum ${ }^{123}$.

57. La protección de la buena fe del $\S 892$ BGB. El tráfico jurídico inmobiliario debe poder confiar en la seguridad y veracidad de lo que publica el Registro, siendo éste el objetivo principal del Grundbuch $^{124}$. Cuando el Registro es inexacto, el adquirente que confía en lo que aparece en el mismo, ha de ser protegido ante la situación real que no está inscrita ${ }^{125}$. Sin tal protección, la importancia del Grundbuch quedaría desacreditada. Dado que la presunción de exactitud carece de efectos legales materiales, el $\S 891$ BGB por sí no basta para proteger el tráfico jurídico. El Grundbuch eleva la situación registralmente publicada, la apariencia jurídica, a una realidad fingida, y así protege a los participantes del tráfico jurídico que actúan sin conocimiento de la inexactitud registral ${ }^{126}$. Los adquirentes que actúan con buena fe, serán protegidos ante reclamaciones fundamentadas en la verdadera situación jurídicoreal, pero no inscrita en el Grundbuch ${ }^{127}$.

58. Mientras que el $\S 891$ BGB se limita a crear una presunción positiva de exactitud tanto de las inscripciones como de las cancelaciones, el § 892 BGB está acompañado por una presunción negativa, según la cual se presumen los derechos y gravámenes no inscritos como no existentes ${ }^{128}$. En otras palabras, cabe confiar en el silencio del Registro ya que el citado artículo establece una presunción de exactitud y de integridad ${ }^{129}$.

59. El bien inmueble y los derechos reales que el adquirente pretende adquirir están inscritos ${ }^{130}$. La protección parte justamente de una inscripción registral, reflejando una determinada situación jurídico-real que, pese a no estar conforme a la realidad, es decir, pese a ser inexacta, provoca una apariencia jurídica ${ }^{131}$.

60. El adquirente y el titular registral que celebran el negocio jurídico dispositivo oneroso, tienen que ser personas distintas. No se aplica el $\S 892$ BGB a disposiciones que derivan de supuestos legales de sucesión.

61. El elemento clave es la buena fe. El adquirente ha de confiar justamente en la exactitud del contenido registral y actuar sobre su base. Solo un conocimiento positivo de la inexactitud excluye la buena fe del adquirente ${ }^{132}$. En comparación con el $\S 932$ BGB, que prevé la adquisición de una cosa mueble del no legitimado, las exigencias de la buena fe son más bajas, resultando en un nivel elevado de protección para quién confía en el Registro ${ }^{133}$. Cabe justificarlo con la fe pública registral que implica una fiabilidad mayor que la posesión.

62. No es necesario que el adquirente haya visto de hecho el asiento registral ${ }^{134}$. Se le protege incluso si no tenía conocimiento del contenido registral. La razón está en que el legislador no sola-

122 J. F. BAuR/ R. StÜRner, Sachenrecht, cit. § 23 I; K. StÖBER, GBO-Verfahren und Grundstückssachenrecht, 2. Auflage, München, 1998, § 1 apdo 67.

${ }^{123}$ R. WeBer, Sachenrecht II - Grundstücksrecht, cit. § 8 apdo 1; K. VIEWEG / A. WeRnER, Sachenrecht, cit. § 13 apdos 8 y 39; K. SтӧвеR, GBO-Verfahren und Grundstückssachenrecht, cit. § 1 apdo 67.

${ }^{124}$ R. WEBER, Sachenrecht II - Grundstücksrecht, cit. § 8 apdo 7.

${ }^{125}$ Münchener Kommentar zum Bürgerlichen Gesetzbuch, 8. Auflage, München, 2020, § 892 apdo 2.

${ }^{126}$ J. Holzer / A. KRAmer, Grundbuchrecht, cit. apdo 104.

${ }^{127}$ J. Holzer / A. KRAMER, Grundbuchrecht, cit. apdo 107.

${ }^{128}$ H. SCHÖNER / K. STÖBER, Grundbuchrecht-Handbuch der Rechtspraxis, cit. § 1 apdo 79.

${ }^{129}$ Münchener Kommentar zum Bürgerlichen Gesetzbuch, 8. Auflage, München, 2020, § 892 apdo 1; K. STÖBER, GBO-Verfahren und Grundstückssachenrecht, cit. § 1 apdo 79; J. Holzer / A. KRAMER, Grundbuchrecht, cit. apdo 104.

${ }^{130}$ Münchener Kommentar zum Bürgerlichen Gesetzbuch, 8. Auflage, München, 2020, § 892 apdo 4.

${ }^{131}$ Münchener Kommentar zum Bürgerlichen Gesetzbuch, 8. Auflage, München, 2020, § 892 apdo 4.

${ }^{132}$ BGH NJW-RR 2013, 789 .

${ }^{133}$ H. Kollhosser, "Das Grundbuch - Funktion, Aufbau, Inhalt", cit. p. 558.

${ }^{134}$ BGH NJW 1980, 2413, 2414. 
mente pretende proteger al adquirente de buena fe, sino que además estima razonable que el verdadero legitimado, el cual haya omitido rogar la inscripción pese a tener la posibilidad, pierda su derecho y su posición jurídico-real ${ }^{135}$.

63. La aplicación del $\S 892$ BGB queda excluida si en el asiento se encuentra inscrita alguna contradicción, dado que la finalidad de ésta consiste en invalidar la presunción de exactitud inherente al $\S 892 \mathrm{BGB}^{136}$.

64. Si todos los requisitos están cumplidos, el adquirente de buena fe lo hace con el alcance y las limitaciones derivadas del Registro. Por consiguiente, cabe decir que la apariencia jurídica sustituye a la realidad ${ }^{137}$. Por un lado, el adquirente se convierte positivamente en el titular legítimo del derecho erróneamente inscrito ${ }^{138}$. Por otro lado, en el sentido negativo, el tercero adquiere el derecho libre de todos gravámenes y cargas inscribibles, pero no inscritos o erróneamente eliminados ${ }^{139}$. Cuando el adquirente de buena fe esté inscrito como nuevo titular del derecho, termina la inexactitud del Registro ${ }^{140}$.

65. De esta manera el que adquirió el derecho de un transmitente ilegítimo es ahora su dueño legítimo. El anterior titular no inscrito no tiene ninguna posibilidad de oponerse a la pérdida de su derecho, al no permitirse prueba de lo contrario, o sea, de la inexactitud registral (presunción iuris et de iure). En su caso, puede reclamar una indemnización al que transmitió el derecho pese a carecer del poder de disposición ${ }^{141}$.

\section{Derecho inmobiliario material en España}

\section{A) Valor y efectos de la inscripción}

66. Correspondiendo al sistema del título y el modo, los requisitos para realizar una transmisión de un derecho real inmobiliario son el previo negocio jurídico-obligacional y la tradición (art. 609 CC). Con la tradición, consistente en la toma de posesión del bien o en la formalización del contrato notarialmente, concluye el proceso de transmisión. No es preciso acudir al proceso de inscripción registral, dado que la mutación jurídico-real se provoca con independencia del Registro. Por eso, la inscripción no es condición intrínseca para el nacimiento del derecho ${ }^{142}$. Tampoco se impone la inscripción extrínsecamente, por ejemplo, por supeditar la existencia del derecho a la formalidad de la inscripción. Se podría hablar de un "principio de no inscripción"143. El Registro se mantiene alejado de la constitución del derecho, no siendo la inscripción necesaria para que la transmisión sea plenamente eficaz inter partes.

67. En el Derecho español, la inscripción no es hecho generador de la transmisión, ni puede sustituir la tradición ${ }^{144}$. El hecho generador es la tradición, por lo cual la inscripción de una mutación jurídica en el Registro de la Propiedad es siempre y de todas formas un acto posterior a la transmisión del

\footnotetext{
${ }^{135}$ R. WeBER, Sachenrecht II - Grundstücksrecht, cit. $\S 8$ apdo 9.

${ }^{136}$ Münchener Kommentar zum Bürgerlichen Gesetzbuch, 8. Auflage, München, 2020, §892 apdo 40.

${ }^{137}$ R. WEBER, Sachenrecht II - Grundstücksrecht, cit. $\S 8$ apdo 8.

${ }^{138}$ Münchener Kommentar zum Bürgerlichen Gesetzbuch, 8. Auflage, München, 2020, §892 apdo 70.

${ }^{139}$ Münchener Kommentar zum Bürgerlichen Gesetzbuch, 8. Auflage, München, 2020, §892 apdo 70.

${ }^{140}$ Münchener Kommentar zum Bürgerlichen Gesetzbuch, 8. Auflage, München, 2020, §892 apdo 69.

141 Wellenhofer, M., Sachenrecht, cit. § 19 apdo 32.

${ }^{142}$ A. Gordillo CAÑAs, "La inscripción en el Registro de la Propiedad (Su contenido causal, su carácter voluntario y su función publicadora de la realidad jurídico-inmobiliaria o generadora de su apariencia jurídica)", cit. p. 53 .

${ }^{143}$ A. Gordillo CAÑAs, "La inscripción en el Registro de la Propiedad (Su contenido causal, su carácter voluntario y su función publicadora de la realidad jurídico-inmobiliaria o generadora de su apariencia jurídica)", cit. p. 42.

${ }^{144}$ J. L. Lacruz Berdejo / J. Delgado Echeverría / J. J. Rams Albesa, Elementos de Derecho Civil. III bis, Derecho inmobiliario registral, cit. p. 106.
} 
derecho e independiente de la misma ${ }^{145}$. Cabe, consecuentemente, decir que "los derechos se publican porque existen, no existen porque se publiquen"146.

68. Sin embargo, la ley prevé algunos supuestos en los que la inscripción adquiere excepcionalmente carácter constitutivo ${ }^{147}$. Sirve como ejemplo el art. 1875 CC, que, para la constitución de una hipoteca sobre una finca, impone como necesaria su inscripción en el Registro de la Propiedad ${ }^{148}$.

69. Un derecho inscribible es un derecho ya nacido y existente, que se basa en un negocio jurídico vigente. Por tanto, la doctrina científica mayoritaria califica la inscripción como "declarativa"149.

70. Sin cuestionar el efecto declarativo de la inscripción, GORDILLO CAÑAS opina que lo que las partes quieren cuando solicitan la inscripción, no es simple y genéricamente declarar la existencia de su derecho, sino que más allá o más específicamente tienen la intención de que terceros interesados tengan conocimiento del derecho real. Entonces, al inscribir el derecho, las partes reafirman su existencia y le dan cognoscibilidad legal con todos los efectos que estén ligados a esta publicación ${ }^{150}$. Por las consecuencias legales que la inscripción provoca, el autor citado prefiere decir que tiene efecto publicador ${ }^{151}$.

71. La inscripción registral se define como un acto cuya realización queda en principio a la libre decisión de las partes ${ }^{152}$. Salvo algunas excepciones, no existen preceptos que establezcan una obligación de inscripción o que impongan un deber de inscripción cuyo incumplimiento fuera sancionable ${ }^{153}$. En su lugar, son exclusivamente las partes las que deciden si quieren publicar la mutación jurídico-real en el Registro o no. La inscripción es por ello voluntaria. El efecto solo declarativo de la inscripción es presupuesto para su voluntariedad ya que una inscripción constitutiva nunca puede ser voluntaria ${ }^{154}$.

72. Sin embargo, se podría decir que la "voluntariedad" es una noción relativa. O dicho más claramente: que el legislador puede promover tal voluntariedad al conectar consecuencias a la inscripción o no inscripción.

73. A pesar de la no necesidad de la inscripción para constituir el derecho, el Registro de la Propiedad debe servir como medio fiable para cumplir con el principio de la publicidad. Debe así facilitar a los participantes del tráfico jurídico la posibilidad de conocer el estado en el que un bien inmueble se encuentra, y otorgar seguridad al tráfico jurídico inmobiliario. Un Registro que solo publica una pequeña fracción de los derechos reales inmobiliarios no cumple esta función ${ }^{155}$.

74. Con la intención de asegurar el buen funcionamiento, el legislador introdujo incentivos legales conectando consecuencias jurídicas beneficiosas a la inscripción y perjudiciales a la no inscripción

${ }^{145}$ B. LöBER, Grundeigentum in Spanien - Handbuch für Eigentümer, Käufer und Verkäufer, cit. p. 41.

${ }^{146}$ A. Gordillo CaÑas, "La inscripción en el Registro de la Propiedad (Su contenido causal, su carácter voluntario y su función publicadora de la realidad jurídico-inmobiliaria o generadora de su apariencia jurídica)", cit. p. 58.

147 J. L. Lacruz Berdejo / J. Delgado Echeverría / J. J. Rams Albesa, Elementos de Derecho Civil. III bis, Derecho inmobiliario registral, cit. p. 97.

${ }_{148}$ M. AlbaladeJo, Derecho Civil III. Derecho de Bienes, cit. § 23 8. y §1231.

${ }^{149}$ M. Albaladejo, Derecho Civil III. Derecho de Bienes, cit. § 142 2; C. S. Rupp, "Germanisches Grundbuch und romanisches Register: Harmonisierende Überlegungen”, cit. 567 y 577.

${ }^{150}$ B. LöBER, Grundeigentum in Spanien - Handbuch für Eigentümer, Käufer und Verkäufer, cit. p. 41.

${ }^{151}$ A. Gordillo Cañas, "La inscripción en el Registro de la Propiedad (Su contenido causal, su carácter voluntario y su función publicadora de la realidad jurídico-inmobiliaria o generadora de su apariencia jurídica)", cit. p. 13.

${ }_{152}$ M. Albaladejo, Derecho Civil III. Derecho de Bienes, cit. § 1421.

${ }^{153}$ B. LöBER, Grundeigentum in Spanien - Handbuch für Eigentümer, Käufer und Verkäufer, cit. p. 41.

${ }^{154}$ A. Gordillo CaÑas, "La inscripción en el Registro de la Propiedad (Su contenido causal, su carácter voluntario y su función publicadora de la realidad jurídico-inmobiliaria o generadora de su apariencia jurídica)", cit. p. 13.

${ }^{155}$ C. FranKenHeIM, Das deutsche Grundbuch und das spanische Eigentumsregister - eine rechtsvergleichende Untersuchung, cit. p. 70 . 
de un derecho ${ }^{156}$. Como ejemplo sirve el art. $313 \mathrm{LH}$, que establece la necesidad de inscribir ciertos documentos para que sean admitidos como medio de prueba ante una autoridad judicial ${ }^{157}$. De tal manera, recomienda a las partes que procedan a la inscripción de la mutación jurídico-real ${ }^{158}$. Generalmente, las partes inscriben su derecho por un doble interés: para reflejar la realidad inmobiliaria y para generar su apariencia jurídica ${ }^{159}$. En este contexto, una parte de la doctrina dice que la inscripción es más bien una carga de quien adquiere un derecho ${ }^{160}$.

75. Un derecho real tiene eficacia erga omnes, debido a lo cual el titular real puede hacer valer su derecho frente a todo el mundo y no solo frente a aquél que le transmitió el derecho. Esta oponibilidad está estrechamente relacionada con el principio de publicidad. Siendo el Registro el medio de publicidad, la no inscripción provoca consecuencias jurídicas en cuanto a la eficacia erga omnes del derecho inscribible.

76. En primer lugar, la inscripción evita que quien inscribe su derecho o la mutación jurídica, pueda ser perjudicado o que le pueda ser opuesto cualquier acto generador de un derecho incompatible con el suyo ${ }^{161}$. Se refiere al "principio del cierre registral" del art. $17.1^{\circ} \mathrm{LH}$. El principio impide que un derecho de igual o anterior fecha pueda acceder al Registro cuando se oponga o sea incompatible con un título traslativo o declarativo del dominio ya inscrito porque transmita o grave la propiedad del mismo inmueble o derecho real ${ }^{162}$. El Registro queda cerrado para actos anteriores incompatibles, no pudiendo el titular del derecho inscrito ser perjudicado en su posición, dado que el titular del derecho no inscrito no tendrá manera de hacerlo valer ${ }^{163}$. Cabe decir que la ley da preferencia a este adquirente o titular real que es el primero en inscribir ${ }^{164}$.

77. El titular queda legitimado erga omnes para ejercitar y hacer valer el derecho inscrito (art. $32 \mathrm{LH}$ ). Un derecho inscrito no puede ser ignorado por el tráfico jurídico, ya que será oponible en todo caso y frente a todo el mundo. Puede, a primera vista, provocar la impresión de que la inscripción registral es el tercer elemento esencial para constituir la eficacia erga omnes de los derechos reales inmobiliarios. ${ }^{165}$ No obstante, por lo general, no es preciso ya que la eficacia absoluta es una característica inherente a todo derecho real ${ }^{166}$. En vez de ello, sería más exacto decir que la eficacia erga omnes queda paralizada mientras el derecho no esté inscrito porque la omisión de la inscripción excluye en determinados supuestos la facultad del titular de oponer su derecho frente a todo el mundo. Más precisamente, los no conocedores de la existencia del derecho pueden alegar la imposibilidad de conocerlo basada en la falta de inscripción. En relación con terceros no conocedores, el titular extra-registral no tendrá la posibilidad de oponerle su derecho; el derecho real es por lo tanto parcialmente privado de su eficacia erga omnes ${ }^{167}$.

${ }^{156}$ A. Gordillo Cañas, "La inscripción en el Registro de la Propiedad (Su contenido causal, su carácter voluntario y su función publicadora de la realidad jurídico-inmobiliaria o generadora de su apariencia jurídica)”, cit. p. 9.

${ }^{157}$ M. Albaladejo, Derecho Civil III. Derecho de Bienes, cit. § 1421.

${ }^{158}$ B. LöBER, Grundeigentum in Spanien - Handbuch für Eigentümer, Käufer und Verkäufer, cit. p. 41.

${ }^{159}$ B. LöBER, Grundeigentum in Spanien - Handbuch für Eigentümer, Käufer und Verkäufer, cit. p. 41.

${ }^{160}$ A. Gordillo CaÑas, "La inscripción en el Registro de la Propiedad (Su contenido causal, su carácter voluntario y su función publicadora de la realidad jurídico-inmobiliaria o generadora de su apariencia jurídica)", cit. p. 68.

${ }^{161}$ A. Gordillo CaÑas, "La inscripción en el Registro de la Propiedad (Su contenido causal, su carácter voluntario y su función publicadora de la realidad jurídico-inmobiliaria o generadora de su apariencia jurídica)", cit. p. 9.

${ }^{162}$ M. Albaladejo, Derecho Civil III. Derecho de Bienes, cit. § 1463.

${ }^{163}$ M. Albaladejo, Derecho Civil III. Derecho de Bienes, cit. § 1463 y ss.

${ }^{164}$ A. Gordillo Cañas, "El principio de fe pública registral (II)”, Anuario de Derecho Civil, Vol. 61, № 3, 2008, pp. 1057 1216, p. 1155.

${ }^{165}$ C. FrankenheIm, Das deutsche Grundbuch und das spanische Eigentumsregister - eine rechtsvergleichende Untersuchung, cit. p. 66.

${ }^{166}$ A. Gordillo CaÑas, "La inscripción en el Registro de la Propiedad (Su contenido causal, su carácter voluntario y su función publicadora de la realidad jurídico-inmobiliaria o generadora de su apariencia jurídica)", cit. p. 16.

${ }^{167}$ A. Gordillo CaÑas, "La inscripción en el Registro de la Propiedad (Su contenido causal, su carácter voluntario y su función publicadora de la realidad jurídico-inmobiliaria o generadora de su apariencia jurídica)”, cit. p. 16. 
77. Al mismo tiempo, y esto es importante ser realzado, frente a los terceros conocedores de la existencia del derecho y de su pertenencia a un determinado titular, éste ya tiene plena eficacia erga omnes y puede ser opuesto, pese a no estar inscrito en el Registro. Frente a terceros con aliunde conocimiento, es decir frente a quien obtuvo conocimiento de la situación jurídico-real por otro medio ajeno al Registro, el titular puede siempre oponer su derecho, sea inscrito o no ${ }^{168}$.

78. Si el que inscribe adquirió el derecho inscrito de quien apareció como su titular, será mantenido en su adquisición, aunque no fuera legítimo dueño. El art. 34 LH regula la "adquisición a non domino". El citado artículo será objeto de análisis en un momento posterior, señalando ahora brevemente que el tercero que actúa de buena fe puede eficazmente adquirir un derecho real inmueble del titular registral, aunque éste no fuera el legítimo dueño ${ }^{169}$. No obstante, este mantenimiento en la adquisición opera únicamente si el adquirente inscribe su derecho en el registro.

\section{B) Fe publica registral}

79. Desde el principio, es decir desde su creación, el Registro de la Propiedad ha sido concebido en función de un objetivo principal: otorgar seguridad al tráfico jurídico ${ }^{170}$.

80. De todos modos, el Registro solo logra su objetivo de ser un medio fiable, si en caso de discordancia entre la situación registral y la situación real, prevalece su contenido. Dado que tener temor ante motivos de ineficacia del contenido, o tener que practicar una comprobación demasiado complicada, faltaría al objetivo del Registro: el de no paralizar el tráfico jurídico por incertidumbres e inseguridades ${ }^{171}$. En lugar de esto, es necesario que el tercero pueda confiar en la apariencia generada por el mismo. Es por ello, que el Registro de la Propiedad español adoptó determinados mecanismos que, a pesar de la inscripción no constitutiva, deben garantizar conseguir la fiabilidad y la exactitud de las inscripciones ${ }^{172}$. Algunos de estos mecanismos son el "principio del tracto sucesivo", la organización por fincas, etc. El "principio de la fe pública", con los efectos que provoca, logra eliminar las incertidumbres para el adquirente. ${ }^{173}$

81. Una de las consecuencias del concepto de la apariencia jurídica es la de presumir la exactitud de una inscripción o cancelación, tanto en cuanto a su existencia como a su pertenencia ${ }^{174}$. Ello está representado por el "principio de legitimación registral" del art. 1 III LH. Se trata de una forma de dar preferencia a la situación registral sobre la situación jurídico-real. Por lo que, mientras que no se pruebe lo contrario, las inscripciones vienen acompañadas por la presunción de su veracidad ${ }^{175}$. La legitimación positiva, según el art. $38 \mathrm{I} \mathrm{LH}$, trae consigo que los derechos inscritos se presumen existentes y pertenecientes al titular registral, solo reconociendo en dicho titular el poder de disposición sobre el derecho

${ }^{168}$ A. Gordillo CAÑas, "La inscripción en el Registro de la Propiedad (Su contenido causal, su carácter voluntario y su función publicadora de la realidad jurídico-inmobiliaria o generadora de su apariencia jurídica)", cit. p. 17.

${ }^{169}$ A. Gordillo CaÑas, "La inscripción en el Registro de la Propiedad (Su contenido causal, su carácter voluntario y su función publicadora de la realidad jurídico-inmobiliaria o generadora de su apariencia jurídica)”, cit. p. 9.

${ }^{170}$ A. Gordillo CAÑAS, "La peculiaridad de nuestro sistema hipotecario frente a los modelos latino y germánico: la publicidad registral como apariencia jurídica", cit. p. 31.

${ }^{171}$ A. Gordillo CaÑas, "La peculiaridad de nuestro sistema hipotecario frente a los modelos latino y germánico: la publicidad registral como apariencia jurídica", cit. pp. 30 y 41.

${ }^{172}$ A. Gordillo CaÑas, "La peculiaridad de nuestro sistema hipotecario frente a los modelos latino y germánico: la publicidad registral como apariencia jurídica”, cit. p. 32.

${ }^{173}$ F. P. MÉndez GonzÁlez, La función de la fe pública registral en la transmisión de bienes inmuebles - un estudio del sistema español con referencia al alemán, cit. p. 65.

${ }^{174}$ G. De Reina Tartière, Gabriel, "El Derecho registral inmobiliario y el Registro de la Propiedad”, cit. p. 54.

${ }^{175}$ F. J. Sánchez Calero / B. Moreno Quesada, Curso de Derecho Civil III, Derechos reales y registral inmobiliario, cit. p. 474; T. A. JimÉnez PARís, La publicidad de los derechos reales y el Registro de la Propiedad en España, VI 1. 
inscrito ${ }^{176}$. La legitimación negativa que está recogida en el art. 97 LH supone la presunción de que un derecho inscribible no inscrito o eliminado no existe. La función principal del principio es la exención de la carga de la prueba en el proceso. Hasta que no se pruebe la falsedad del Registro, basta que el titular registral pruebe su derecho con el extracto registral. ${ }^{177}$

82. El "principio de legitimación" del art. 38 LH por sí solo no basta para proteger al tráfico jurídico cuando hay una discordancia entre la apariencia jurídica del Registro y la situación real ${ }^{178}$. La protección del tercero que se acoge al Registro, es decir, que celebra negocios jurídicos sobre la base de la situación registral, es un mecanismo esencial para garantizar la seguridad del tráfico de los inmuebles ${ }^{179}$. El tercero es quién es inducido a error por la no inscripción -sea la omisión intencional o por descuido del titular-y debe por ello ser protegido ante la situación jurídico-real no inscrita cuando confía en la veracidad de los asientos registrales ${ }^{180}$.

83. La jurisprudencia del Tribunal Supremo y la doctrina están conformes en que el art. 34 I LH pretende legitimar la adquisición a non domino, es decir, pese a no ser el transmitente el titular legítimo, respondiendo por lo tanto a la necesidad de defender los intereses del adquirente frente a reclamaciones del legítimo titular no inscrito ${ }^{181}$.

84. Sin embargo, permitir una adquisición de una persona que carece del respectivo poder de disposición es un mecanismo extraño al Derecho civil, sobre todo por la regla fundamental de "nemo dat quod non habet" 182 . Como consecuencia, la operatividad del art. $34 \mathrm{LH}$ ha de ser reducida al mínimo y permitida solamente en casos excepcionales y plenamente justificados ${ }^{183}$.

85. El beneficiario, es decir, el sujeto protegido por la fe pública registral, ha de ser un "tercero". Esto significa que el adquirente del derecho real de dominio o de un derecho real limitativo del dominio debe ser una persona extraña a la relación jurídica que originó la anterior inscripción registral ${ }^{184}$.

86. El tercero adquiere su derecho real a título oneroso de quien, según lo publicado en el Registro, tiene facultades para transmitirlo ${ }^{185}$. Asimismo, el art. $33 \mathrm{LH}$ aclara que la inscripción registral no puede convalidar un acto precedente que fuera nulo. Por lo tanto, el negocio jurídico obligacional, al ser la causa para la transmisión, tiene que ser vigente ${ }^{186}$.

\footnotetext{
${ }^{176}$ M. AlbaladeJo, Derecho Civil III. Derecho de Bienes, cit. § 146 4; B. LöBer, Grundeigentum in Spanien - Handbuch für Eigentümer, Käufer und Verkäufer, cit. p. 28.

${ }^{177}$ F. J. SÁnchez Calero / B. Moreno Quesada, Curso de Derecho Civil III, Derechos reales y registral inmobiliario, cit. p. 475.

${ }^{178}$ A. Gordillo CAÑas, "La peculiaridad de nuestro sistema hipotecario frente a los modelos latino y germánico: la publicidad registral como apariencia jurídica", cit. p. 30; C. FrAnKenheIm, Das deutsche Grundbuch und das spanische Eigentumsregister - eine rechtsvergleichende Untersuchung, cit. p. 86.

179 A. GoRdillo CAÑAS, "La peculiaridad de nuestro sistema hipotecario frente a los modelos latino y germánico: la publicidad registral como apariencia jurídica", cit. p. 39.

${ }^{180}$ C. Frankenheim, Das deutsche Grundbuch und das spanische Eigentumsregister - eine rechtsvergleichende Untersuchung, cit. p. 86; A. GoRDILlo CAÑAS, "La peculiaridad de nuestro sistema hipotecario frente a los modelos latino y germánico: la publicidad registral como apariencia jurídica", cit. pp. 32, 39.

${ }^{181}$ SSTS de 12 abril 1980 y de 25 de octubre de 2004; L. Díez-Picazo Ponce de León, Fundamentos de Derecho Civil Patrimonial, Tomo III, Aranzadi, Pamplona, 2008, § 311.

${ }^{182}$ T. A. JimÉnez París, La publicidad de los derechos reales y el Registro de la Propiedad en España, cit. I.

${ }^{183}$ F. P. MÉndez GonzÁLez, La función de la fe pública registral en la transmisión de bienes inmuebles - un estudio del sistema español con referencia al alemán, cit. pp. 33 y ss.

${ }^{184}$ M. Albaladejo, Derecho Civil III. Derecho de Bienes, cit. § 146 5; A. Gordillo Cañas, "El principio de fe pública registral (I)", Anuario de Derecho Civil, Vol. 59, N² 2, 2006, p. 562; L. Díez-PicAzo Ponce de León, Fundamentos de Derecho Civil Patrimonial, cit. § 23.

${ }^{185}$ C. Frankenheim, Das deutsche Grundbuch und das spanische Eigentumsregister - eine rechtsvergleichende Untersuchung, cit. p. 87; L. Díez-Picazo Ponce de León, Fundamentos de Derecho Civil Patrimonial, cit. § 12.

${ }^{186}$ J. L. Lacruz Berdejo / J. Delgado Echeverría / J. J. Rams Albesa, Elementos de Derecho Civil. III bis, Derecho inmobiliario registral, cit. p. 180.
} 
87. El requisito esencial, o, incluso, "la ratio determinante de la medida legal protectora" 187 , es la buena fe del tercero adquirente. En su antigua concepción, el art. 34 LH no estableció claramente la exigencia de la "buena fe". Sin embargo, ya entonces era evidente que dicho precepto no podía tratar de proteger a una persona de mala fe, dado que personas conocedoras de la inexactitud registral no merecían ninguna protección especial ${ }^{188}$. Al contrario, el tercero será única y exclusivamente protegido en la medida en que confió de buena fe en la veracidad del Registro ${ }^{189}$. En el precepto aludido, "buena fe" se refiere a la creencia del tercero de que el titular registral es el dueño de la cosa, y con ello, que goza del poder de disposición necesario para llevar a cabo el acto de transmisión ${ }^{190}$. Cree que adquiere del legitimado e ignora al mismo tiempo la verdadera falta de titularidad o la existencia de otras circunstancias que no consten en el Registro y puedan hacer ineficaz o limitar la titularidad que aparece en el mismo ${ }^{191}$.

88. Conforme al art. $34.2 \mathrm{LH}$, se presume la buena fe, resultando de una inversión de la carga de la prueba ${ }^{192}$. Según la jurisprudencia del Tribunal Supremo, el art. 34 LH despliega todas sus consecuencias en beneficio del tercero, mientras la parte interesada no demuestre la mala fe de modo pleno, cumplido y manifiesto, que no deje lugar a dudas ${ }^{193}$. Si no logra tal prueba, el tercero puede adquirir el derecho real a non domino por favorecerle la presunción iuris tantum del desconocimiento de la inexactitud registral. La presunción opera incluso cuando el tercero no haya consultado el Registro ${ }^{194}$. La aplicación del mecanismo protector depende finalmente de que el tercero inscriba el derecho adquirido, bajo las circunstancias mencionadas, en el Registro de la Propiedad.

89. Dispone el art. $34 \mathrm{LH}$ que "se le mantendrá en su adquisición" al tercero que reúna todos los requisitos antes tratados. Sin embargo, ha surgido una discusión doctrinal provocándose la pregunta de si, pese a la falta del poder de disposición del transmitente, el tercero de buena fe debe adquirir el verdadero dominio sobre la cosa, como es típico en los sistemas germánicos, o si solo trata de protegerle ante reivindicaciones, mecanismo propio del sistema romano ${ }^{195}$.

90. Lo característico es que el tercero confía en lo que el Registro pública. Esto le hace digno merecedor de la especial protección conectada a la fe pública registral ${ }^{196}$. En beneficio del tercero adquirente, se eleva su expectativa a una presunción iuris et de iure de veracidad, dado que ni siquiera la prueba de inexactitud del Registro podrá afectarle en su derecho ${ }^{197}$. Dicho más claramente, para el tercero de buena fe la apariencia jurídica se convierte en realidad, correspondiendo al principio de que las consecuencias de lo ajeno y desconocido no le puedan perjudicar ${ }^{198}$. Al equipararse inmediata y directamente la apariencia y la realidad, el tercero adquiere el derecho en la medida y extensión en que el

${ }^{187}$ A. Gordillo Cañas, "El principio de fe pública registral (I)”, cit. p. 578

188 J. L. Lacruz Berdejo / J. Delgado Echeverría / J. J. Rams Albesa, Elementos de Derecho Civil. III bis, Derecho inmobiliario registral, cit. p. 182.

${ }^{189}$ L. Díez-Picazo Ponce de León, Fundamentos de Derecho Civil Patrimonial, cit.§ 311.

${ }^{190}$ STS de 2 julio 1965.

${ }^{191}$ M. Albaladejo, Derecho Civil III. Derecho de Bienes, cit. § 146 5; A. Gordillo Cañas, "El principio de fe pública registral (I)", cit. p. 580.

${ }^{192}$ A. Gordillo Cañas, "El principio de fe pública registral (I)”, cit. p. 651; J. L. Lacruz Berdejo / J. Delgado Echeverría / J. J. Rams Albesa, Elementos de Derecho Civil. III bis, Derecho inmobiliario registral, cit. p. 189.

${ }^{193}$ L. Díez-Picazo Ponce de León, Fundamentos de Derecho Civil Patrimonial, cit. § 313.

${ }^{194}$ A. Gordillo Cañas, "El principio de fe pública registral (I)”, cit. p. 596.

${ }^{195}$ A. Gordillo CaÑas, "El principio de fe pública registral (II)”, cit. pp. 1149 y ss.; A. MAnZANo Solano, "Las instituciones registrales en los países occidentales", cit. p. 586.

${ }^{196}$ A. Gordillo Cañas, "El principio de fe pública registral (I)”, cit. p. 560.

${ }^{197}$ L. Díez-Picazo Ponce de León, Fundamentos de Derecho Civil Patrimonial, cit. § 4 20; A. Gordillo Cañas, "El principio de fe pública registral (II)", cit. p. 1133; F. J. Sánchez Calero / B. Moreno Quesada, Curso de Derecho Civil III, Derechos reales y registral inmobiliario, cit. p. 476.

${ }^{198}$ A. GoRdillo CAÑAS, "La peculiaridad de nuestro sistema hipotecario frente a los modelos latino y germánico: la publicidad registral como apariencia jurídica”, cit. p. 41. 
Registro lo publica como perteneciente al titular señalado ${ }^{199}$. Cualesquiera que sean los vicios ignorados por el Registro de la Propiedad por falta de inscripción, y cualesquiera que sean las acciones que extraregistralmente puedan existir ${ }^{200}$, el titular extra-registral $u$ otros interesados no pueden de ninguna manera atacar la posición del tercero de buena fe que tenga su derecho inscrito. Por lo tanto, la protección va más allá de una protección meramente subjetiva frente a reivindicaciones ${ }^{201}$. Según opinión general de la doctrina, el art. $34 \mathrm{LH}$ prevé la adquisición a non domino, pudiendo el adquirente de buena fe hacer valer su derecho a todos los efectos inherentes a un derecho real y en todo coincidente con lo que publique el Registro ${ }^{202}$.

91. Consecuentemente, el efecto del art. 34 LH cumple con su objetivo de garantizar la protección de quien confía en la apariencia jurídica generada por los asientos registrales, tanto en cuanto a su veracidad como a su integridad, al convertir la posición adquirida según Registro en una posición inatacable ${ }^{203}$.

\section{Conclusiones de la comparación}

92. En cuanto a la organización formal del Registro, tanto el sistema alemán como el español adoptan el sistema del "folio real". Los asientos de inscripción que afectan a una determinada finca son agrupados en un mismo folio, relacionando así todos los cambios en derechos o titularidades que repercuten en la situación jurídico-real del bien inmueble. Quien tiene interés en conocer el estado actual de un inmueble solamente tiene que examinar el folio, al reflejar éste el historial jurídico de la finca. Las diferencias entre el Registro de la Propiedad español y el Grundbuch son mínimas y afectan nada más que a la estructura interna del folio real, como al orden de los distintos tipos de derechos reales.

93. Asimismo, ambos Registros se parecen en principio al adoptar un régimen de publicidad formal relativo, limitándola a personas que demuestran tener un interés legítimo en conocer los datos jurídicos de la finca. Sin embargo, mientras que el derecho registral español concede el derecho a consultar el Registro solamente a personas con un interés patrimonial, la jurisprudencia alemana ${ }^{204}$ desarrolló un concepto más abierto de la legitimación y reconoce más motivos. De todos modos, es inevitable ponderar los intereses contrapuestos entre el del derecho a la intimidad del titular inscrito por un lado y el del solicitante que pretende conocer el estado jurídico-real por otro.

94. La diferencia fundamental entre los dos sistemas está en la función de la inscripción. En Alemania, la inscripción es principalmente elemento integral del proceso transmisor para adquirir la propiedad sobre un bien inmueble. Por ejemplo, la inscripción es constitutiva de la producción del cambio en la situación jurídico-real. En España, en cambio, se produce fuera del Registro de la Propiedad. La inscripción es consiguientemente un acto posterior a la transmisión y se limita a tener efectos de publicidad. Sin embargo, ambos sistemas conocen excepciones a su regla general. De esta manera, aunque en el Derecho español la inscripción es fundamentalmente publicadora, puede excepcionalmente adquirir efecto constitutivo, imponiendo consiguientemente el concepto alemán. Como ejemplo, puede citarse la constitución de una hipoteca o del derecho de superficie, que requieren en todo caso la inscripción. En

${ }^{199}$ A. Gordillo Cañas, "El principio de fe pública registral (II)”, cit. p. 1133; F. J. Sánchez Calero / B. Moreno Quesada, Curso de Derecho Civil III, Derechos reales y registral inmobiliario, cit. p. 476.

${ }^{200}$ L. Díez-Picazo Ponce de León, Fundamentos de Derecho Civil Patrimonial, cit. § 420.

${ }^{201}$ A. Gordillo Cañas, "El principio de fe pública registral (II)", cit. p. 1156.

${ }^{202}$ L. Díez-Picazo Ponce de León, Fundamentos de Derecho Civil Patrimonial, cit. § 4 20; A. Gordillo Cañas, "El principio de fe pública registral (II)", cit. p. 1133; L. Lacruz Berdejo / J. Delgado Echeverría / J. J. Rams Albesa, Elementos de Derecho Civil. III bis, Derecho inmobiliario registral, cit. p. 214.

${ }^{203}$ A. Gordillo Cañas, "El principio de fe pública registral (II)”, cit. p. 1132; F. J. Sánchez Calero / B. Moreno Quesada, Curso de Derecho Civil III, Derechos reales y registral inmobiliario, cit. p. 478.

${ }^{204}$ BVerfG NJW 2001, 503. 
el Derecho registral alemán existen supuestos en que la efectiva transmisión prevalece sobre el principio de la inscripción constitutiva. Como consecuencia, el efecto de la inscripción se limita a ser declarativo, como en el régimen español.

95. Al ser indispensable para provocar la transmisión, en Alemania, los adquirentes de un derecho no tienen otra opción sino inscribirlo. La inscripción es obligatoria. Por otra parte, el derecho registral español, por su independencia entre inscripción y proceso transmisor, deja la inscripción a la libre decisión de las partes. El legislador no impone ninguna obligación ni conecta sanciones a la no inscripción, pero establece varios beneficios supeditados a la inscripción que deben motivar la inscripción.

96. Por el principio de separación y abstracción que domina todo el derecho civil alemán, los requisitos para solicitar una inscripción en el Grundbuch están en todos los aspectos desconectados del negocio jurídico obligacional, siendo suficiente el acuerdo real. La práctica de una inscripción en el Registro de la Propiedad español requiere la presentación del título, siendo éste la causa para la transmisión del derecho.

97. Lo destacable es que, aunque los principios de inscripción son, por así decir, contrapuestos, en ambos sistemas registrales la inscripción trae consigo las mismas consecuencias jurídicas. Aunque el Registro de la Propiedad español está -en cuanto al valor de la inscripción- concebido conforme a la tradición romana, el efecto de la inscripción es el propio del sistema germánico, pues conecta consecuencias igualmente fuertes a la inscripción, pese a existir el riesgo de una discordancia entre Registro y realidad mayor que en un sistema con inscripción constitutiva. Los dos sistemas atribuyen fe pública a los asientos registrales y los relacionan con presunciones de exactitud, facilitando de esta forma la adquisición de buena fe y protegiendo el tráfico jurídico en la medida más eficaz.

98. Las diferencias entre el sistema alemán y el sistema español parecen relativamente insignificantes en su conjunto. El único aspecto esencial en el que los sistemas se distinguen es el de la inscripción, que por un lado es constitutiva del derecho y, por otro lado, solamente publicadora. Sin embargo, el sistema español conecta las mismas consecuencias jurídicas a la inscripción, consiguiendo el mismo alcance de publicidad positiva. Sería por tanto una modificación relativamente pequeña hacer la inscripción obligatoria o subordinar la eficacia del derecho real a la condición de su inscripción. De esta manera, el Derecho español podría mantener su principio de la transmisión por título y modo, con una inscripción posterior al nacer el derecho con el acto de la tradición.

\section{El establecimiento de un Registro de la Propiedad Común Europeo}

99. Tras haber estudiado las diferencias entre dos sistemas registrales europeos, el alemán y el español, esta parte del trabajo se centrará sobre la pregunta de si sería posible establecer un Registro de la Propiedad Común Europeo. En el marco de esta pregunta resulta pertinente empezar con un breve panorama de la situación actual del Derecho civil en la Unión Europea - y del derecho real en concretoindicando los enfoques precedentes que van dirigidos al establecimiento de un Ordenamiento civil común, para luego proceder a la presentación de las condiciones legales para una armonización, o incluso unificación, de los sistemas registrales nacionales, y las perspectivas de su realización en el contexto de sus ventajas e inconvenientes.

100. Aunque la Unión Europea no es un Estado y carece de su propio Código civil, todos los Estados Miembros comparten una Constitución Económica ${ }^{205}$. La misma incluye, por un lado, la liber-

\footnotetext{
${ }^{205}$ S. VAN ERP, "Cross-Border Electronic Conveyancing: overcoming problems with negative and positive integration in European property law", European Property Law Journal, 2012, 1 (1), pp. 3 y 5; M. ScHÜRHECK, "Sachenrecht im Europäischen Gemeinschaftsrecht. Bestandsaufnahme, Legislativkompetenzen, Entwicklungsperspektiven”, Osnabrück JMCE Award, Series Nr. 03, 2011, p. 15.
} 
tad de todo individuo de actuar autónomamente en el tráfico jurídico privado, sin que el Estado pueda interferir en gran medida ${ }^{206}$. Correspondientemente, el propietario de una cosa puede, por regla general, ejercer su derecho sin intervención estatal. Por otro lado, los Tratados Europeos establecen las cuatro libertades fundamentales que caracterizan y definen el mercado interior europeo: la libre circulación de personas, bienes, servicios y capitales ${ }^{207}$. Pese a ejercer estas libertades una influencia considerable sobre todos los Ordenamientos jurídico-privados de los Estados Miembros, la Unión tiene solamente competencias limitadas en cuanto a su armonización ${ }^{208}$. Esto se debe, en primer lugar, al reparto de competencias entre la Unión Europea y los Estados Miembros ${ }^{209}$.

101. Como todo organismo supranacional, la Unión Europea deriva sus competencias de los Estados miembros, que delimitan el marco competencial dentro del cual la Unión puede actuar y adoptar medidas legislativas y así desarrollar progresivamente el derecho derivado. Generalmente, el funcionamiento y el poder de la Unión Europea se construye sobre el "principio de atribución de competencias" 210 [arts. 1(1) y 5.1 y 2 TUE y 7 TFUE]. Por lo tanto, tiene competencias limitadas y de carácter exclusivamente funcional ${ }^{211}$. Con respecto al Derecho privado, los Estados Miembros siguen teniendo la competencia general, mientras que la Unión está limitada a realizar intervenciones puntuales cuando resulta ser necesario para garantizar las libertades fundamentales ${ }^{212}$.

102. Lo problemático es que todo Ordenamiento civil nacional cuenta con su propia historia y tradición jurídica, de lo cual resultan diferencias entre un país y otro respecto a su mentalidad jurídica ${ }^{213}$. En los derechos reales, lo que por algunos autores es llamado "el núcleo del derecho civil", las diferencias son especialmente profundas ${ }^{214}$. En aras de reforzar el mercado interior de la Unión Europea, en algunas ocasiones se exigió la creación de un ordenamiento civil europeo, que unificara los preceptos nacionales y elimina así todas las diferencias existentes ${ }^{215}$.

\section{Draft Common Frame of Reference (DCFR)}

103. Fruto del trabajo conjunto del "Grupo de Estudios para el Código Civil Europeo" ("Study Group on a European Civil Code", o "Grupo Von BAR") ${ }^{216}$ y del Research Group on the Existing

${ }^{206}$ A. Hatje/ J. Schwarze, “Der Zusammenhalt der Europäischen Union”, European Law Review, 2019, pp. 153 y 156; S. VAN ERP, "Cross-Border Electronic Conveyancing: overcoming problems with negative and positive integration in European property law", cit. pp. 3 y 5; M. PAschKe / C. Iliopoulos, Europäisches Privatrecht - Ein Studienbuch zum Privatrecht der Europäischen Gemeinschaft, Hamburg, 1998, p. 6.

${ }^{207}$ S. VAN ERP, "Cross-Border Electronic Conveyancing: overcoming problems with negative and positive integration in European property law”, cit. pp. 3 y 5; M. PASCHKE / C. Iliopoulos, Europäisches Privatrecht - Ein Studienbuch zum Privatrecht der Europäischen Gemeinschaft, cit. p. 6.

${ }^{208}$ M. PaschKe / C. Iliopoulos, Europäisches Privatrecht - Ein Studienbuch zum Privatrecht der Europäischen Gemeinschaft, cit. p. 10.

${ }^{209}$ J. EiCKELBERG, "Mitgliedstaatliche Kompetenzen im Registerverfahren im Spannungsfeld zum europäischen Primär- und Sekundärrecht", Zeitschrift für das Privatrecht der Europäischen Union (GPR) 2/2016, pp. 93 y 94.

210 J. Alcaide Fernández /R. Casado Raigón, Curso de Derecho de la Unión Europea, $3^{\mathrm{a}}$ Edición, Tecnos, Madrid, 2018, p. 60.

${ }^{211}$ K. MüLler / U. Gruber, Sachenrecht, München, 2016, pp. 13 y 17.

${ }^{212}$ STJUE de 15/05/2003, Salzmann, apdo 39; STJUE de 23/09/2003, Ospelt, apdo 24; M. PASchKe / C. Iliopoulos, Europäisches Privatrecht - Ein Studienbuch zum Privatrecht der Europäischen Gemeinschaft, cit. pp. 11 y ss.; M. SCHÜRHECK, "Sachenrecht im Europäischen Gemeinschaftsrecht. Bestandsaufnahme, Legislativkompetenzen, Entwicklungsperspektiven”, cit. p. 17.

${ }^{213}$ BASEDOw, "Grundlagen des Europäischen Privatrechts", Juristische Schulung, 2004, pp. 89 y 90; P. Ulmer, "Vom deutschen zum europäischen Privatrecht?”, JuristenZeitung, 1992, pp. 1 y 5; Van Erp, EPLJ 2012, 3, 5.

${ }^{214}$ S. VAN ERP, "Cross-Border Electronic Conveyancing: overcoming problems with negative and positive integration in European property law", cit. pp. 3 y 5.

${ }^{215}$ Resolution on action to bring into line the private law of the Member States (D.O.C.E. C 158, 26.6.1989, p. 400).

${ }^{216}$ Sobre el "Study Group" o "Grupo Von BAR", puede consultarse: M. Martín CASALS, "Els principis del Dret contractual europeu i la Codificació del Dret català", $1 r$. Congrés de Dret civil català: el Dret patrionial en el futur Codi civil de Catalunya, La Notaría, 11-12, 2001, pp. 51-61; E. Roca Trias, E., "El "Study Group a European Civil Code" (Proyecto Von Bar)", en Cámara Lapuente (Coord.), Derecho Privado Europeo, Colex, Madrid, 2003, pp. 199-204; C. Von Bar, "Il grupo di studi su 
EC Private Law, comunmente denominado como el "Acquis Group ${ }^{217}$, dentro de la red de excelencia "Joint Network on European Private Law", financiada por el "Sexto Programa Marco" de la Unión Europea", y cumpliendo con el "Plan de Acción" diseñado en la Comunicación de la Comisión al Parlamento Europeo y al Consejo de 12 de febrero de 2003, elaboraron un "Borrador del Marco Común de Referencia" ("Draft Common Frame of Reference" o "DCFR"), base de un futuro Common Frame of Reference ("CFR") 218 .

104. Cumpliendo los compromisos asumidos con la Comisión, el "Study Group" y el "Acquis Group" presentaron el día 29 de diciembre de 2007 un borrador provisional de CFR integrado por principios, definiciones y reglas modelo de Derecho privado europeo, que fue publicado a principios del año $2008^{219}$. Posteriormente, a principios del año 2009 , se publicó una segunda edición revisada ${ }^{220}$ y, finalmente, la publicación completa, acompañada de comentarios, notas de Derecho comparado y una lista de definiciones, fue publicada en septiembre de $2009^{221}$.

105. El DCFR se divide en tres partes, que ya habían sido sugeridas por la Comunicación de la Comisión al Parlamento Europeo y al Consejo de 11 de octubre de $2004^{222}$, y se corresponden con su propia denominación de Principles, Definitions and Model Rules ${ }^{223}$ :

- Principles ${ }^{224}$ : el DCFR se construye sobre cuatro principios esenciales que son la libertad, la seguridad, la justicia y la eficiencia. De cada uno de estos principios básicos o universales que impregnan su texto, los drafters destacan una serie de aspectos. Por ejemplo, al tratar del principio de seguridad, se refiere a la buena fe y la lealtad, el deber de cooperar, etc.

un Codice Civile Europeo", en Alpa/Buccico (dirs.), Il Codice Civile Europeo. Materiali dei seminari 1999-2000. Raccolti da Guido Alpa e Emilio Nicola Buccico, Giufrè, Milano, 2001, pp. 3-19.

${ }^{217}$ Sobre el "Acquis Group", vid., entre otros: E. Arroyo i Amayuelas, "Hacia un derecho contractual más coherente: La sistematización del acervo contractual comunitario", en Bosch CAPDEvilla (coord.), Derecho Contractual Europeo, (director Esteve Bosch Capdevila, coordinador Decanato del Colegio de Registradores de Catalunya), Editorial Bosch, Barcelona, 2009, pp. 209-238; G. A. Benacchio/ B. Pasa, A Common Law for Europe, Central European University Press, Budapest-New York, 2005, pp. 294-296; S. Leible, "Vías para la unificación del Derecho privado europeo", (traducción Francisco Infante Ruiz), Anuario de Derecho Civil, 2006, pp. 1606 y 1607; R. SchUlze, "European Private Law and Existing EC Law", European Rewiev of Private Law, 13/1, 2005, pp. 3-19.

${ }^{218}$ Existe una amplia bibliografía sobre el DCFR académico y su proceso de gestación, vid., entre otros: H. BEALE, “The future of the Common Frame of Reference", European Review of Contract Law, 3, 2007, pp. 257-276; J. M. DE LA CUESTA Rute, "Sobre la unificación del Derecho privado patrimonial en Europa", en Valpuesta Gastaminza (coord.), Unificación del Derecho Patrimonial Europeo. Marco común de referencia y Derecho español, Bosch, Barcelona, 2011, pp. 23-59; O. LANDO, "The Structure and the Legal Values of the Common Frame of Reference (CFR)", European Review of Contract Law, 3, 2007, pp. 245-256; L. MiLLER, «The Common Frame of Reference and the feasibility of a common contract law in Europe", Journal of Bussiness Law, 4, 2077, pp. 378-411; M. Oderkerk, "The CFR and the Method(s) of Comparative Legal Research", European Review of Contract Law, 3, 2007, pp. 315-331; M. SсHAUB, "The Common Frame of Reference and the Future of European Contract Law-Society of European Contract Law (SECOLA) ", European Review of Private Law, 15/5, 2007, pp. 751-755.

${ }^{219}$ Study Group on a European Civil Code, Research Group on EC Private Law (Acquis Group), Principles, Definitions and Model Rules of European Private Law. Draft Common Frame of Reference (DCFR), edited by Christian Von Bar, Eric Clive and Hans Schulte-Nölke, Interim Outline Edition, Seller, Munich, 2008.

${ }^{220}$ Study Group on a European Civil Code, Research Group on EC Private Law (Acquis Group), Principles, Definitions and Models Rules of European Private Law. Draft Common Frame of Reference (DCFR), edited by Christian Von Bar, Eric Clive and Hans Schulte-Nölke, Outline Edition, Seller, Munich, 2009.

${ }^{221}$ Study Group on a European Civil Code, Research Group on EC Private Law (Acquis Group), Principles, Definitions and Model Rules of European Private Law. Draft Common Frame of Reference (DCFR), edited by Christian Von Bar and Eric Clive, Full Edition, vols. I a VI, Oxford University Press, Oxford-New York, 2010.

${ }^{222}$ «La estructura prevista para el MCR (véase un ejemplo en el anexo I) es la siguiente: en primer lugar, se enunciarían los principios fundamentales comunes de Derecho contractual, incluyendo directrices para las eventuales excepciones a dichos principios. En segundo lugar, dichos principios fundamentales estarían apoyados mediante definiciones de conceptos claves. En tercer lugar, los principios y las definiciones se completarían mediante normas tipo, que constituirían el núcleo del MCR».

${ }^{223}$ En la Introducción del volumen I de la Full Edition justifican los drafters el por qué del contenido del DCFR, cit. pp. 4-10.

${ }^{224}$ Volumen I de la Full Edition del DCFR, cit. pp. 37-63. 
- Definitions ${ }^{225}$ : la falta de definición de muchos términos empleados en las Directivas ha sido una de las aporías que han influido negativamente en el ideal armonizador, puesto que su ausencia ha motivado que en la transposición de las mismas por los Estados se produjeran discrepancias entre los significados empleados en las Directivas y los adoptados por las legislaciones nacionales. Como remedio ante tales males, el DCFR ofrece una amplia lista de definiciones, que no sólo pretenden evitar cualquier tipo de error en la interpretación de los conceptos utilizados en sus reglas modelo, sino que posibilitarían que los legisladores nacionales puedan acudir a dicha lista de definiciones, y que así adopten con su propia terminología la expresión más adecuada al sentido correcto de la norma y sus términos. En definitiva, esta lista de definiciones supone una herramienta de gran valor para la hermenéutica contribuyendo al desarrollo de una terminología legal uniforme europea.

- Model Rules: son el núcleo del DCFR y configuran un conjunto de normas coherentes, resultado no sólo de la labor de indagación de los principios transcendentales del acervo comunitario realizada por el "Acquis Group", sino también de las mejores soluciones existentes en los Ordenamientos nacionales y en otros textos jurídicos de carácter internacional, como la Convención de Viena sobre Compraventa Internacional de Mercaderías (CISG), lo que es principalmente resultado de la labor realizada por el "Study Group" como heredero de la "Comisión Lando". La estructura interna de las reglas modelo es idéntica a la de los Principles of European Contract Law (PECL). Primero, el texto del artículo (black letter rule) va presidido por su título y de forma escueta recoge el mandato normativo en letra negrilla, acompañado del comentario que, a manera de interpretación auténtica, tiene por objeto exponer los razonamientos que han llevado a sus redactores a adoptar dicha norma, así como cuál es su objetivo y su funcionamiento correcto. Dicho comentario contiene supuestos prácticos (illustrations). Y, finalmente, una nota en la que se contienen referencias a las fuentes de inspiración de las reglas adoptadas, siendo éstas no sólo de los diversos Ordenamientos jurídicos de los Estados Miembros, la CISG y los Principles International Commercial Contracts (PICC), sino también las Directivas de la Unión Europea ${ }^{226}$.

106. Respecto a la estructura y contenido del DFCR debe indicarse que su publicación se ha realizado en seis volúmenes, divididos, además de en los principios básicos y en las definiciones, en díez libros que, a su vez, se subdividen en capítulos, secciones, subsecciones y, por último, en artículos. Su contenido ha sobrepasado con mucho el de los PECL, ya que el DCFR establece reglas relativas no sólo a lo que podríamos denominar teoría general del contrato, sino que también regula determinados tipos de contratos, responsabilidad precontractual, enriquecimiento injusto, propiedad mobiliaria, truts, etc..., lo que lleva a algún autor a afirmar que el DCFR ha tenido «la intención de agotar el derecho del tráfico patrimonial moderno» ${ }^{227}$.

107. Finalmente, debe indicarse, respecto a lo que es objeto del presente estudio, que aunque una parte del DCFR se ocupa de los derechos reales ${ }^{228}$, sin embargo, el derecho registral inmobiliario,

\footnotetext{
${ }^{225}$ Volumen I de la Full Edition del DCFR, cit. pp. 65-82.

${ }^{226}$ En relación a la estructura interna de las model rules se afirma en la Introducción del DCFR que «the comments explain the objective of the particular model rule, place it in the context of the DCFR as a whole and, where appropiate, provide information about its origins and discuss possible alternative solutions. Illustrations, often derived from court cases in the Member States, are provided as an aid to understanding the effects of the rule. The notes give the present legal position in the Member States and in Comunity law (where available). International instruments such as the UN Convention on Contracts for the International Sale of Goods (CISG) and the Unidroit Principles of International Commercial Contracts 2004 are also mentioned where appropiate. How the notes were assembled is described in the section on the academic contributors. Whenever possible, an attempt is made to state the law of all Member States up to about the middle of 2008. However, smaller research teams sometines had to be content with a more limited range of legal systems», volumen I de la Full Edition del DCFR, cit. p. 3.

${ }^{227}$ J. M. De la Cuesta Rute, "Sobre la unificación del Derecho privado patrimonial en Europa", cit. p. 25.

${ }^{228}$ S. MARTENS, "Ein Europa, ein Privatrecht - Die Bestrebungen zur Vereinheitlichung des Europäischen Privatrechts", Europäische Zeitschrift für Wirtschaftsrecht, 2010, pp. 527 y 528.
} 
quedó excluido de su ámbito de estudios, presumiblemente porque, debido a las diferencias, el grupo de trabajo no pudo llegar a una solución consensual229.

\section{Integración positiva y negativa}

108. Pese a no estar el derecho inmobiliario registral incluido en el DCFR, los preceptos nacionales siguieron evolucionando congruentemente por una integración positiva y negativa ${ }^{230}$. En principio, la integración en su vertiente positiva se refiere a la asimilación de las leyes nacionales a través de la adopción de Reglamentos y Directivas ${ }^{231}$. Ciertamente, hasta la actualidad, la Unión se ha resistido en adoptar una medida legislativa con repercusión en el derecho registral estatal ${ }^{232}$. En algunas medidas, ha sido excluido expresamente de su ámbito de aplicación ${ }^{233}$.

109. En cuanto a la integración negativa, emanada de la jurisprudencia europea, cabe hacer algunas observaciones ${ }^{234}$. Las libertades fundamentales de la Unión Europea pueden desplegar efectos sobre aspectos del derecho real nacional. Aun así, no da lugar a una armonización sino es nada más que una limitación de los Estados Miembros en el ejercicio de sus competencias legislativas ${ }^{235}$.

110. Para señalar un ejemplo contrario, el Tribunal de Justicia de la Unión Europea declaró admisible que la autoridad estatal que lleva el Registro de la Propiedad, requiera al peticionario de una inscripción presentar un documento firmado por un Notario de este mismo Estado Miembro ${ }^{236}$. Dada la posibilidad de rechazar documentos certificados en otros países europeos, hay autores que cuestionan la conformidad con el principio de la libre prestación de servicios ${ }^{237}$.

\section{European Land Information Service (EULIS)}

111. En todo caso, no es posible ignorar la evolución de un mercado interior que, generalmente, sigue abriéndose. Cada vez es mayor el número de ciudadanos europeos que viven y trabajan en otro país comunitario ${ }^{238}$. Conforme a esto, cada vez más personas adquieren un bien inmueble en el extranjero y se ven confrontadas con las grandes diferencias legales. Sigue dominando la opinión de que este ámbito es de responsabilidad y competencia estatal, por lo que la Unión Europea se abstuvo de legislar el derecho real y, formando parte de éste, el derecho registral ${ }^{239}$.

${ }^{229}$ C. Von Bar / E. Clive, Principles, Definitions and Model Rules of European Private Law, Draft Common Frame of Reference (DCFR), Full Edition, 2009, p. 4207.

${ }^{230}$ S. VAN ERP, "Cross-Border Electronic Conveyancing: overcoming problems with negative and positive integration in European property law”, cit. pp. 3 y 4.

${ }^{231}$ S. VAN ERP, "Cross-Border Electronic Conveyancing: overcoming problems with negative and positive integration in European property law", cit. p. 3.

${ }^{232}$ J. EICKELBERG, "Mitgliedstaatliche Kompetenzen im Registerverfahren im Spannungsfeld zum europäischen Primär- und Sekundärrecht", cit. pp. 93 y 95.

${ }^{233}$ Ejemplos: art. 1 II lit. b) de la Directiva 2008/122/CE, del Parlamento y del Consejo, de 14 de enero de 2009; Consideración (18) y art. 1 II lit. 1) del Reglamento n. 650/2012, del Parlamento Europeo y del Consejo, de 4 de julio de 2012.

${ }^{234}$ S. VAN ERP, "Cross-Border Electronic Conveyancing: overcoming problems with negative and positive integration in European property law", cit. pp. 3 y 4.

${ }^{235}$ M. SCHÜRHECK, "Sachenrecht im Europäischen Gemeinschaftsrecht. Bestandsaufnahme, Legislativkompetenzen, Entwicklungsperspektiven", cit. p. 20.

${ }^{236}$ STJUE de 09/03/2017, C-324/15, Piringer.

${ }^{237}$ S. VAN ERP, "Cross-Border Electronic Conveyancing: overcoming problems with negative and positive integration in European property law", cit. pp. 3 y 8.

${ }^{238}$ S. VAN ERP, "Cross-Border Electronic Conveyancing: overcoming problems with negative and positive integration in European property law", cit. pp. 3 y 6.

${ }^{239}$ J. EiCKELBERG, "Mitgliedstaatliche Kompetenzen im Registerverfahren im Spannungsfeld zum europäischen Primär- und Sekundärrecht”, cit. pp. 93 y 95; S. VAN ERP, "Cross-Border Electronic Conveyancing: overcoming problems with negative and positive integration in European property law", cit. pp. 3 y 7. 
112. Mientras que no haya uniformidad en las reglas, gana en importancia la necesidad de que se armonice la política de información entre los países para asegurar el funcionamiento del mercado interior $^{240}$. Quien quiera adquirir un bien inmueble en otro país comunitario debe tener la posibilidad de conocer su estado jurídico-real ${ }^{241}$. En la actualidad, es una práctica común contratar un asesor local con conocimiento de la terminología y práctica legal del respectivo país ${ }^{242}$.

113. Para facilitar el procedimiento, en el año 2002, la Unión Europea inició el proyecto EULIS, en el cual participaron al principio ocho Estados ${ }^{243}$. Interconecta los Registros de la Propiedad de varios países europeos y permite así su acceso transfronterizo ${ }^{244}$. Trata, pues, de poner los derechos inscritos en un Registro nacional a disposición de un ciudadano de otro país que esté interesado ${ }^{245}$. De esta manera proporciona información de la situación jurídico-real de un bien inmueble para facilitar la adquisición. Además de remitir al interesado al Registro de la propiedad nacional, incorpora información adicional sobre la situación legal y el funcionamiento del Registro en el respectivo país ${ }^{246}$. Esto es muy importante al ser uno de los obstáculos principales en el tráfico de bienes inmuebles a nivel supraestatal puesto que el valor legal de la información registral cambia entre un sistema y otro ${ }^{247}$. La mera puesta a disposición de los datos traería consigo un riesgo de malinterpretación si faltan definición o aclaración de las leyes y prácticas nacionales ${ }^{248}$. Por lo tanto, EULIS incluye resúmenes del significado legal y del alcance de los derechos reales presentes en el ordenamiento civil. Además, clarifica y traduce los términos legales, desarrollando de tal manera una terminología jurídica común europea ${ }^{249}$.

114. EULIS constituye un primer paso que eleva la transparencia en transacciones inmobiliarias, pero simultáneamente plantea la duda de si puede sobrevivir mientras los sistemas registrales diferentes no se acerquen por lo menos en parte ${ }^{250}$. Pensando más allá, el próximo paso lógico sería la armonización del derecho registral a nivel europeo ${ }^{251}$.

\section{Competencia legislativa de la Unión Europea en derecho inmobiliario registral}

115. Como ya se ha dicho anteriormente, la Unión Europea tiene solamente competencias funcionales y requiere un título adjuntado en los Tratados fundacionales que le faculte para legislar comu-

${ }^{240}$ H. Ploeger / B. Van Loenen, "EULIS - At the beginning of the Road to Harmonization in Land Registry in Europe", European Review of Private Law, 2004, p. 379.

${ }^{241}$ S. VAN ERP, "Cross-Border Electronic Conveyancing: overcoming problems with negative and positive integration in European property law", cit. pp. 3 y 7.

${ }^{242}$ H. Ploeger / B. VAn Loenen, "EULIS - At the beginning of the Road to Harmonization in Land Registry in Europe", cit. pp. 183 y 186.

${ }^{243}$ H. Ploeger / B. Van Loenen, "EULIS - At the beginning of the Road to Harmonization in Land Registry in Europe", cit. pp. 379 y 383.

${ }^{244}$ H. Ploeger / B. VAn Loenen, "EULIS - At the beginning of the Road to Harmonization in Land Registry in Europe", cit. pp. pp. 379 y 383.

${ }^{245}$ J. F. BAUR/ R. STÜRNER, Sachenrecht, cit. § 64 apdo 79.

${ }^{246}$ H. Ploeger / B. VAn Loenen, "EULIS - At the beginning of the Road to Harmonization in Land Registry in Europe", cit. pp. 379 y 385 .

${ }^{247}$ F. Molina Balaguer, “¿Hacia un Registro Europeo de la Propiedad? La lucha contra el blanqueo de capitales: análisis de la situación vigente y de la propuesta de V Directiva anti-blanqueo desde el punto de vista registral”, Revista Crítica de Derecho Inmobiliario, núm. 763, Septiembre, 2017, pp. 2393 y 2428; H. Ploeger / B. VAN Loenen, "EULIS - At the beginning of the Road to Harmonization in Land Registry in Europe", cit. pp. 379 y 385; C. S. Rupp, "Germanisches Grundbuch und romanisches Register: Harmonisierende Überlegungen", cit. pp. 567 y 569.

${ }^{248}$ H. Ploeger / B. VAn Loenen, "EULIS - At the beginning of the Road to Harmonization in Land Registry in Europe", cit. pp. 379 y 385 .

${ }^{249}$ H. Ploeger / B. VAn Loenen, "EULIS - At the beginning of the Road to Harmonization in Land Registry in Europe", cit. pp. 379 y 384 .

${ }^{250}$ J. F. BAUR/ R. StÜRnER, Sachenrecht, cit. § 64 apdo 79.

${ }^{251}$ H. Ploeger / B. VAn Loenen, "EULIS - At the beginning of the Road to Harmonization in Land Registry in Europe", cit. p. 379. 
nitariamente en derecho inmobiliario registral. Al no existir un título específico, los artículos competenciales tratados en lo sucesivo se refieren mayoritariamente a supuestos más generales, siendo el derecho registral una materia incluida.

116. La aplicabilidad de un título competencial a una situación concreta tiene que ser examinado sobre criterios objetivos y en función al objetivo y contenido del derecho secundario que debe ser creado, art. 5 I y II TUE 252 .

117. El art. 345 TFUE, que puede ser calificado como norma competencial negativa ${ }^{253}$, establece que los Tratados no prejuzgan en modo alguno el régimen de la propiedad de los Estados Miembros. La Unión debe pues abstenerse de influir en los regímenes nacionales de la propiedad ${ }^{254}$. Sin poner en cuestión que existe una relación entre el derecho registral y el derecho de propiedad ${ }^{255}$, la respuesta a la cuestión de la competencia para crear un Registro de la Propiedad Europeo no resulta tan clara, dado que el alcance del art. 345 TFUE es muy controvertido. Especialmente, respecto al significado del término "régimen de la propiedad", del que se han conformado varias concepciones doctrinales, influidas sobre todo por el objetivo legal y la génesis de la norma ${ }^{256}$.

118. La opinión dominante estima, atendiendo al enunciado del artículo, que el "régimen de la propiedad" se limita a tales normas y conceptos que regulan la existencia y las limitaciones públicas de la institución jurídica "propiedad" 257 . La Unión Europea, entonces, no puede menoscabar el derecho a la propiedad privada de tal manera que sea incompatible con las constituciones estatales, donde se recogen las decisiones fundamentales relativos al derecho de la propiedad ${ }^{258}$. Por regla general, los textos constitucionales se limitan a garantizar y proteger el derecho subjetivo de tener un bien en su propiedad privada e imponer al Estado la obligación de desarrollar por leyes los correspondientes conceptos y modos de adquisición, sin especificar el cómo ${ }^{259}$.

119. Conforme a esta interpretación tiene lugar la génesis del art. 345 TFUE. Tras la Segunda Guerra Mundial, Francia e Italia tenían muchas empresas y compañías en propiedad pública, por lo que los Estados consideraron la necesidad de aclarar que ellos mismos seguirían teniendo la competencia dentro del margen legítimo previsto ${ }^{260}$. Así, la intención principal perseguida con la norma es impedir que la Unión Europea se atribuya el derecho de realizar privatizaciones o socializaciones de empresas y compañías privadas ${ }^{261}$.

${ }^{252}$ K. MÜlLer / U. Gruber, Sachenrecht, cit. pp. 13 y 17; M. SchÜRHECK, "Sachenrecht im Europäischen Gemeinschaftsrecht. Bestandsaufnahme, Legislativkompetenzen, Entwicklungsperspektiven”, cit. S. 27.

${ }^{253}$ STJUE de 20/10/1993 C-92/92 y C-326/92.

${ }^{254}$ L. M. Cabello de los Cobos y Mancha, "La Propiedad inmobiliaria y el Derecho de la Construcción en las Directivas Comunitarias", en Díaz Fraile (coord.), Estudios de Derecho Europeo Privado, Centro de Estudios Registrales, Madrid, 1994, pp. 261-364, p. 279.

${ }^{255}$ F. Molina Balaguer, “¿Hacia un Registro Europeo de la Propiedad? La lucha contra el blanqueo de capitales: análisis de la situación vigente y de la propuesta de V Directiva anti-blanqueo desde el punto de vista registral”, cit. pp. 2393 y 2428.

${ }^{256}$ C. Calliess / M. Ruffert, Kommentar EUV/AEUV, Das Verfassungsrecht der Europäischen Union mit Europäischer Grundrechtecharta, 5. Auflage, München, 2016, Art. 345 apdo 9.

${ }^{257}$ B. AkKermans / E. RamaeKers, “Article 345 TFEU (ex Article 295 EC), Its Meanings and Interpretations”, European Law Journal, 16, 2010, pp. 302 y ss; M. SсHÜRHECK, "Sachenrecht im Europäischen Gemeinschaftsrecht. Bestandsaufnahme, Legislativkompetenzen, Entwicklungsperspektiven”, cit. p. 27.

${ }^{258}$ C. CAlliess / M. Ruffert, Kommentar EUV/AEUV, Das Verfassungsrecht der Europäischen Union mit Europäischer Grundrechtecharta, Art. 345 apdos 10 y ss.; R. STREINZ, Kommentar EUV/AEUV, Vertrag über die Europäische Union, Vertrag über die Arbeitsweise der Europäischen Union, Charta der Grundrechte der Europäischen Union, 3. Auflage, München 2018, Art. 345, apdo 14.

${ }^{259}$ S. STORR, "Die Vorschläge der EU-Kommission zur Verschärfung der Unbundling-Vorschriften im Energiesektor”, Europäische Zeitschrift für Wirtschaftsrecht, 2007, pp. 232 y 235.

${ }^{260}$ R. Streinz , Kommentar EUV/AEUV, Vertrag über die Europäische Union, Vertrag über die Arbeitsweise der Europäischen Union, Charta der Grundrechte der Europäischen Union, 3. Auflage, München 2018, Art. 345, apdo 3.

${ }^{261}$ R. STREINZ, Kommentar EUV/AEUV, Vertrag über die Europäische Union, Vertrag über die Arbeitsweise der Euro- 
120. Según otra opinión doctrinal, el art. 345 TFUE excluye toda competencia legislativa de la Unión en el ámbito del derecho real. Niega así también la competencia de la Unión Europea para establecer un Registro de la Propiedad Común Europeo, argumentando que es un mecanismo a través del cual el Estado define y garantiza el derecho de la propiedad y los demás derechos reales. Los actos legislativos comunitarios, dirigidos a introducir cambios en el derecho registral a nivel europeo, pueden afectar a los regímenes nacionales de transmisión de propiedad en sentido del art. 345 TFUE ("régimen de la propiedad") ${ }^{262}$. Según esta interpretación, el art. 345 TFUE tendría un efecto de veto que impediría la creación de un Registro Europeo de la Propiedad, al menos "por parte de las autoridades de la Unión" $" 263$.

121. Sin embargo, esta opinión no es sostenible, ya que casi todo acto legislativo repercute sobre el derecho a la propiedad. Con esta interpretación, las competencias de la Unión Europea serían demasiado limitadas ${ }^{264}$. Ello indica que el art. 345 TFUE debe ser aplicado restrictivamente ${ }^{265}$. En consecuencia, el art. 345 TFUE no afecta las competencias comunitarias para desarrollar un régimen comunitario del derecho de propiedad y, consiguientemente, tampoco un sistema registral común, siempre que respete los regímenes nacionales ${ }^{266}$.

122. El art. 50 II lit. e) TFUE dispone que no es admisible que un Estado Miembro perjudique a un nacional de otro Estado Miembro en la adquisición y el aprovechamiento de propiedades inmuebles situados en el propio territorio. Sin embargo, existe un convencimiento generalizado de que este precepto no debe ser entendido como amplia atribución competencial que faculte a la Unión a regular todo aspecto del derecho inmobiliario ${ }^{267}$. La Unión Europea no puede justificar cualquier armonización de las reglas nacionales relativas a la adquisición y pérdida o al uso de la propiedad en base del art. 50 II lit. e) TFUE.

123. En el marco de establecer un régimen común de normas de conflicto de leyes, la Unión Europea puede adoptar medidas de aproximación de las disposiciones legales y reglamentarias de los Estados Miembros, incluyendo fundamentalmente también el derecho inmobiliario registral ${ }^{268}$. No obstante, el título competencial del art. 81 TFUE se refiere exclusivamente a la adopción de normas de orden procesal y justamente no prevé una armonización material ${ }^{269}$. No es un título apto para crear un Registro de la Propiedad Común Europeo.

päischen Union, Charta der Grundrechte der Europäischen Union, cit. Art. 345 apdo 4; B. AkKermans / E. RamaEKERs, "Article 345 TFEU (ex Article 295 EC), Its Meanings and Interpretations", cit. p. 305; W. DRASCH, "Die Rechtsgrundlagen des europäischen Einheitsrechts im Bereich des gewerblichen Eigentums (Artt. 100 a, 235, 36 und 222 EGV)", Zeitschrift für Europäisches Privatrecht, 1998, pp. 118, 127; C. CALLIEss / M. RufFerT, Kommentar EUV/AEUV, Das Verfassungsrecht der Europäischen Union mit Europäischer Grundrechtecharta, cit. Art. 345 apdo 2.

${ }^{262}$ F. Molina BAlaguer, “¿Hacia un Registro Europeo de la Propiedad? La lucha contra el blanqueo de capitales: análisis de la situación vigente y de la propuesta de V Directiva anti-blanqueo desde el punto de vista registral", cit. pp. 2393 y 2428.

${ }^{263}$ F. Molina Balaguer, “¿Hacia un Registro Europeo de la Propiedad? La lucha contra el blanqueo de capitales: análisis de la situación vigente y de la propuesta de V Directiva anti-blanqueo desde el punto de vista registral”, cit. pp. 2393 y 2428.

${ }^{264}$ R. STREINZ, Kommentar EUV/AEUV, Vertrag über die Europäische Union, Vertrag über die Arbeitsweise der Europäischen Union, Charta der Grundrechte der Europäischen Union, cit. Art. 345 AEUV, apdo 13.

${ }^{265}$ M. SCHÜRHECK, "Sachenrecht im Europäischen Gemeinschaftsrecht. Bestandsaufnahme, Legislativkompetenzen, Entwicklungsperspektiven", Osnabrück JMCE Award, Series Nr. 03, 2011, cit. p. 28.

${ }^{266}$ B. Akkermans / E. Ramaekers, "Article 345 TFEU (ex Article 295 EC), Its Meanings and Interpretations", European Law Journal, 16, 2010, pp. 292 y 314; W. DRASCH, "Die Rechtsgrundlagen des europäischen Einheitsrechts im Bereich des gewerblichen Eigentums (Artt. 100 a, 235, 36 und 222 EGV)", cit. 118 y 127.

267 J. EiCKELBERG, "Mitgliedstaatliche Kompetenzen im Registerverfahren im Spannungsfeld zum europäischen Primär- und Sekundärrecht", cit. pp. 93 y 95.

268 J. F. BAuR/ R. STÜRnER, Sachenrecht, 18, Auflage, München, 2009, cit. § 64 apdo 74.

${ }^{269}$ M. SсHÜRHECK, "Sachenrecht im Europäischen Gemeinschaftsrecht. Bestandsaufnahme, Legislativkompetenzen, Entwicklungsperspektiven”, cit. p. 28; R. STREInZ, Kommentar EUV/AEUV, Vertrag über die Europäische Union, Vertrag über die Arbeitsweise der Europäischen Union, Charta der Grundrechte der Europäischen Union, cit. Art. 81 apdo 44. 
124. El Parlamento Europeo y el Consejo adoptarán las medidas relativas a la aproximación de las disposiciones legales, reglamentarias y administrativas de los Estados Miembros. que tengan por objeto el establecimiento y el funcionamiento del mercado interior.

125. El art. 114 TFUE es un título competencial general para promover la armonización de normativa estatal. Dado que no existe otra norma más específica aplicable, podría en principio servir como base para armonizar el derecho inmobiliario registral ${ }^{270}$. Debido a su concepción muy amplia y la consiguiente universalidad, el Tribunal de Justicia de la Unión Europea en el pasado dictó varias sentencias oponiéndose a una interpretación demasiado amplia. Por lo tanto, la aplicabilidad del título competencial está restringida a la consecución de determinados objetivos ${ }^{271}$.

126. Es imprescindible que el cambio vaya dirigido a una armonización del contenido de leyes nacionales perfeccionando el funcionamiento del mercado interior ${ }^{272}$. Esta armonización puede ser alcanzada, aunque en distintos grados, o bien por un Reglamento, que siempre lleva a una homogeneización, o bien por una Directiva, que también permite establecer criterios mínimos comunes ${ }^{273}$. La creación de una nueva autoridad administrativa, como la del Registro de la Propiedad, está cubierta por su ámbito de aplicación siempre que sirva al cumplimiento del Derecho comunitario ${ }^{274}$.

127. Las diferencias entre las leyes nacionales coexistentes, cuya armonización se pretende, suponen un obstáculo concreto al ejercicio de las libertades fundamentales ${ }^{275}$. Las diferencias entre los sistemas registrales implican un riesgo para adquirentes que no conocen el valor legal de la inscripción en el Estado miembro en que pretenden adquirir un bien inmueble. Aunque pueden contratar un asesor local y el precio es presumiblemente bajo en comparación con los valores inmobiliarios, los distintos sistemas sí reducen la seguridad jurídica y presentan por tanto un obstáculo a la adquisición de un bien inmueble. Los ciudadanos europeos pueden verse limitados en el ejercicio de su derecho a la libre circulación que les permite poder vivir y trabajar en el extranjero europeo.

128. El último requisito exige que el funcionamiento del mercado interior se mejore como consecuencia de la armonización ${ }^{276}$. Puede incluso ir más allá de eliminar barreras comerciales cuando esté motivada por una política de integración ${ }^{277}$. Dado que, desde un punto de vista hipotético, las diferencias entre los distintos Registros de la Propiedad implican un obstáculo, su eliminación en todo caso perfeccionará la posibilidad de ejercer las libertades civiles y así el funcionamiento del mercado interior de la Unión Europea ${ }^{278}$.

${ }^{270}$ J. BASEDOW, "Die Entwicklung des Eigentumsrechts in der Europäischen Union”, Zeitschrift für Europäisches Privatrecht, 2016, pp. 573 y 579.

${ }^{271}$ STJUE de 05/10/2000 C-376/98 apdo 84; STJUE de 12/12/2006 C-380/03 apdos 36 y ss.; GHN EU/Tietje, AEUV Art. 114 apdo 6.

${ }^{272}$ R. STREINZ , Kommentar EUV/AEUV, Vertrag über die Europäische Union, Vertrag über die Arbeitsweise der Europäischen Union, Charta der Grundrechte der Europäischen Union, cit. Art. 114 apdo 19.

${ }^{273}$ M. SCHÜRHECK, "Sachenrecht im Europäischen Gemeinschaftsrecht. Bestandsaufnahme, Legislativkompetenzen, Entwicklungsperspektiven", cit. p. 29.

${ }^{274}$ C. CALLIESS / M. RufFert, Kommentar EUV/AEUV, Das Verfassungsrecht der Europäischen Union mit Europäischer Grundrechtecharta, cit. Art. 114 apdo 25.

${ }^{275}$ R. STREInZ, Kommentar EUV/AEUV, Vertrag über die Europäische Union, Vertrag über die Arbeitsweise der Europäischen Union, Charta der Grundrechte der Europäischen Union, cit. Art. 114 apdo 19.

${ }^{276}$ A. InNS, Entwicklung und Grundlagen der europäischen Rechtsangleichung, Frankfurt a.M., 2005, Art. 114 apdo 46.

${ }^{277}$ M. MöstL, "Grenzen der Rechtsangleichung im Europäischen Binnenmarkt - Kompetenzielle, grundfreiheitliche und grundrechtliche Schranken des Gemeinschaftsgesetzgebers", European Law Review, 2002, pp. 318 у 324.

${ }^{278}$ M. SCHÜRHECK, "Sachenrecht im Europäischen Gemeinschaftsrecht. Bestandsaufnahme, Legislativkompetenzen, Entwicklungsperspektiven”, cit. p. 33. 
129. Los requisitos del art. 114 TFUE se complementan con el criterio de la necesidad del art. 5.4 TFUE ${ }^{279}$. Para elevar la seguridad del tráfico de bienes inmuebles y reforzar el mercado interior, la implantación de un sistema registral común es una medida adecuada y necesaria.

130. El art. 114 TFUE, que establece un título de competencia general a favor de la Unión Europea, parece ser apropiado para crear un Registro común. No obstante, también hay autores que, sobre todo con respecto al art. 345 TFUE, expresan sus dudas con tal facultad, y hay que reconocer que sus argumentos no son injustificados. Ciertamente, la pregunta de si la Unión es competente o no, depende en gran parte de la configuración final del Registro.

\section{Perspectivas}

\section{A) Perspective and Feasibility \& Implementation Analysis (2014)}

131. La Comisión Europea encargó a un grupo que elaborase un estudio de viabilidad para decidir si se debería desarrollar un Registro de la Propiedad para el e-Justice Portal, tal como, en su momento se hizo con el proyecto EULIS. Sobre la base de determinados criterios, el análisis recopila datos sobre los distintos sistemas registrales; por ejemplo, que casi todos están digitalizados y que la mayoría de los Estados Miembros llevan el Registro por títulos en vez de utilizar el "deed recording system". Según sus resultados, el sistema registral deberá incluir traducciones lo más íntegras posible e información dirigida a clarificar el valor legal y las posibilidades de uso de los datos obtenidos. En general, propone una implantación progresiva para poder asegurar el buen funcionamiento, sobre todo a la luz de la diversidad legal.

\section{B) Directiva (UE) 2018/843 del Parlamento Europeo y del Consejo, de 30 de mayo de 2018}

132. En la citada Directiva se insertó el nuevo artículo 32 ter, dirigido al establecimiento de un sistema supraestatal para facilitar a las autoridades competentes el acceso a datos relativos a la identificación de propietarios de bienes inmuebles sitos en otro Estado Miembro ${ }^{280}$.

133. De todos modos, lo más llamativo y posiblemente innovador en cuanto a la solución de la presente duda competencial se encuentra en el apartado 2. Que establece que, hasta el 31 de diciembre de 2020, la Comisión deberá presentar un informe al Parlamento Europeo y al Consejo, evaluando la necesidad y proporcionalidad de armonizar la información incluida en los Registros de la propiedad y la necesidad de interconectar los respectivos registros nacionales. Por el momento, es este informe del que depende la evolución de una posible interconexión de los registros nacionales, posiblemente en forma de un registro de la propiedad europeo común ("European real property register"281).

\section{C) Técnica legislativa adecuada}

134. La técnica legislativa habrá de adaptarse a la naturaleza del proyecto ${ }^{282}$. El art. 288 TFUE enumera los posibles instrumentos jurídicos de los que la Unión Europea dispone. Normas por las que

${ }^{279}$ R. STREINZ, Kommentar EUV/AEUV, Vertrag über die Europäische Union, Vertrag über die Arbeitsweise der Europäischen Union, Charta der Grundrechte der Europäischen Union, cit. Art. 114 apdo 63.

${ }^{280}$ F. Molina Balaguer, “¿Hacia un Registro Europeo de la Propiedad? La lucha contra el blanqueo de capitales: análisis de la situación vigente y de la propuesta de V Directiva anti-blanqueo desde el punto de vista registral”, cit. pp. 2393 y 2395.

${ }^{281}$ F. Molina Balaguer, “¿Hacia un Registro Europeo de la Propiedad? La lucha contra el blanqueo de capitales: análisis de la situación vigente y de la propuesta de V Directiva anti-blanqueo desde el punto de vista registral", cit. pp. 2393 y 2424.

${ }^{282}$ F. Molina Balaguer, “¿Hacia un Registro Europeo de la Propiedad? La lucha contra el blanqueo de capitales: análisis de la situación vigente y de la propuesta de V Directiva anti-blanqueo desde el punto de vista registral", cit. pp. 2393, 2426 y ss. 
se realiza un proyecto como la creación de un registro de la Propiedad Europeo deben ser de aplicación general y directa, sin que los Estados Miembros puedan ajustar los preceptos según su gusto. Los propios Tratados constitutivos sirven para establecer normas y procedimientos a seguir por las instituciones comunitarias $^{283}$. Aparte, el Reglamento satisface todas las características jurídicas exigidas por ser obligatorio y vinculante en todos sus elementos y por no dar lugar a una diferencia en aplicación entre los Estados Miembros, siendo por lo tanto la técnica pertinente para dirigirse a instituciones propias de la Unión Europea ${ }^{284}$.

\section{D) Posible configuración}

135. Ampliando la vista a todos los Estados Miembros de la Unión Europea, en la regulación del derecho inmobiliario existen diferencias en algunos aspectos, sobre todo en comparación con el deed-system de los países de Common Law. A pesar de ello, en puntos claves sigue un concepto común. Algunas propuestas de armonización, que siguen siendo hipotéticas, prevén un sistema registral similar al de tradición germánica.

136. En todos los sistemas registrales la inscripción tiene por lo menos un efecto declarativo o publicador. Igualmente, un Registro de la Propiedad Europeo Común tendría que aplicar el principio de la publicidad formal y prever el derecho de consultar los asientos registrales, posiblemente según distintos grados de interés ${ }^{285}$.

137. A nivel europeo, se puede incluso observar una tendencia hacia una inscripción con efectos constitutivos no solamente frente a terceros, sino ya inter partes ${ }^{286}$. Por lo tanto, tal solución sería recomendable para una armonización de los sistemas nacionales. Ofrece la opción de establecer excepciones, en las cuales la transmisión del derecho real se produce fuera del Registro y la inscripción es posterior y declarativa.

138. Un aspecto menos consolidado es la "publicidad positiva", como la conocen los países de tradición germánica, pero también España y los Estados Miembros occidentales. La mayoría de los sistemas sigue limitándola a la publicidad negativa. Sin embargo, un sistema de publicidad positiva, que vincula fuertes efectos a la inscripción, sería conveniente. Especialmente al considerar que, gracias a la llevanza electrónica de los registros, la práctica de la inscripción es hoy más fácil y económica que antes. Sistemas que adoptan la publicidad positiva sustraen el máximo beneficio de la institución registral al garantizar la mayor protección del tráfico jurídico, asegurando tanto claridad como seguridad jurídica.

\section{E. Viabilidad}

139. Por último, en evaluación de los aspectos anteriormente analizados y tras haber analizado la posibilidad teórica de legislar en el ámbito registral, planteamos la pregunta de si una armonización podría ser viable, exponiendo a continuación sus ventajas e inconvenientes.

140. Con mucha insistencia se exige desde hace años la creación de un régimen de derechos de garantía -cabe mencionar la propuesta de la "eurohipoteca" excesivamente discutida-para facilitar transmisiones transfronterizas de cualquier tipo que requieren la prestación de una garantía. Dependien-

${ }^{283}$ F. Molina Balaguer, “¿Hacia un Registro Europeo de la Propiedad? La lucha contra el blanqueo de capitales: análisis de la situación vigente y de la propuesta de V Directiva anti-blanqueo desde el punto de vista registral", cit. pp. 2393 y 2427.

${ }^{284}$ J. Alcaide Fernández /R. CASAdo Raigón, Curso de Derecho de la Unión Europea, cit. p. 189.

${ }^{285}$ C. S. RupP, “Germanisches Grundbuch und romanisches Register: Harmonisierende Überlegungen”, cit. pp. 567 y 575.

286 J. F. BAUR/ R. STÜRNER, Sachenrecht, cit. § 64 apdo 83. 
do de la configuración final de esta seguridad real, puede ser necesario que previamente se establezca algún sistema de publicidad, en el cual tales derechos reales limitativos puedan ser inscritos ${ }^{287}$.

141. Como ya se ha indicado en varias ocasiones a lo largo de este trabajo, la creación de un Registro de la Propiedad Común Europeo iría dirigida al reforzamiento del mercado interior de la Unión Europea por facilitar y garantizar el ejercicio de las libertades civiles fundamentales. Ya que, mediante el establecimiento de un registro transfronterizo, todas las ventajas y funciones de los nacionales se transferirían a nivel europeo.

142. Entre los inconvenientes se encuentran que la creación de Registro es un proyecto costoso $^{288}$; el sistema registral ha de ser configurado asegurando el buen funcionamiento del Registro; ha de establecerse una autoridad responsable con funcionarios que lo lleven y mantengan. Además, es esencial que la autoridad tenga representaciones locales en todo momento accesible por los participantes del tráfico jurídico, por lo menos mientras no sea enteramente digitalizado. Luego, en el supuesto de que siga existiendo una autoridad nacional que lleve el registro a nivel local, es necesario repartir las competencias para evitar conflictos.

143. El derecho registral está estrechamente relacionado con el derecho real material. El Registro se adapta a las necesidades materiales y, al revés, el derecho material tiene su base en las reglas formales que aseguran el cumplimiento de los principios del derecho material ${ }^{289}$. A nivel nacional, tal interrelación se ha desarrollado a lo largo de mucho tiempo, perfeccionándose progresivamente para ser hoy un sistema coherente, que además cuenta con una alta legitimación democrática y vela por la justicia social ${ }^{290}$. También con otros ámbitos legales, como el derecho concursal, con el que el Registro de la Propiedad está altamente relacionado. La interacción entre un ámbito legal comunitariamente armonizado y los demás ámbitos legales no armonizados, es decir nacionales, ha de ser asegurada ${ }^{291}$.

144. Desde un punto de vista de política legal, una intervención radical, pero todavía fragmentaria, en tales sistemas consolidados y conocidos, imponiendo un sistema enteramente nuevo todo a la vez, podría causar cierto desorden al afectar a la seguridad jurídica y provocaría efectos más bien contrapuestos a los objetivos de una armonización ${ }^{292}$.

145. El Derecho civil es expresión de la tradición legal de un país. Unificar los sistemas nacionales llevaría a la pérdida de la cultura jurídica europea versátil ${ }^{293}$. Los ciudadanos, y sobre todo los juristas, están orgullosos de esta tradición y se identifican con el Ordenamiento civil que emana de la misma. Es por ello dudoso si los Estados Miembros renunciarían a su propio sistema registral para formalizar compromisos con los demás países.

${ }^{287}$ H. Ploeger / B. Van Loenen, "The European Real Estate Market - Transparency, Security and Certainty through registration by EuroTitle", en Van Erp / SAlomons / AkKermans (edit.), The Future of European Property Law, Berlin 2012, pp.183 y 187; C. S. Rupp, "Germanisches Grundbuch und romanisches Register: Harmonisierende Überlegungen", cit. pp. 567 y 569 ; S. Van Erp /B. Akkermans, "Public or Private Harmonisation of the EU Mortgage Market", Zeitschrift für Europäisches Privatrecht, 2013, pp. 43 y 53.

${ }^{288}$ En general: H. Kӧтz, "Rechtsvereinheitlichung - Nutzen, Kosten, Methoden, Ziele”, Rabels Zeitschrift für europäisches und internationales Privatrecht, 1986, 1, 2.

${ }^{289}$ C. S. Rupp, "Germanisches Grundbuch und romanisches Register: Harmonisierende Überlegungen”, cit. 567 y 569.

${ }^{290}$ J. F. BAUR/ R. STÜRnER, Sachenrecht, cit. § 64 apdo 80.

${ }^{291}$ A. IHNS, Entwicklung und Grundlagen der europäischen Rechtsangleichung, cit. pp. 188 y ss.

${ }^{292}$ P. Ulmer, "Vom deutschen zum europäischen Privatrecht?", cit. 1, 6; H. KöтZ, "Rechtsvereinheitlichung - Nutzen, Kosten, Methoden, Ziele", Rabels Zeitschrift für europäisches und internationales Privatrecht, cit. 1, 12.

${ }^{293}$ O. SANDROCK, "Das Privatrecht am Ausgang des 20. Jahrhunderts: Deutschland - Europa - und die Welt", JuristenZeitung, 1996, 1, 7. 


\section{Conclusiones finales}

146. Aunque los órganos de la Unión Europea más de una vez han declarado la necesidad de promover la armonización del Derecho civil para perfeccionar el mercado interior, faltan esfuerzos serios y nada hace pensar en la creación de un Registro de la Propiedad Común Europeo a corto plazo ${ }^{294}$. Los sistemas registrales de los Estados Miembros son diferentes y su unificación exige a algunos países hacer renuncias notables. Por esta razón, supone un gran desafío tanto legal como organizativo para la comunidad europea ${ }^{295}$. Una manera más viable en el camino hacia el establecimiento de un Registro común sería la armonización progresiva de los correspondientes a cada uno de los países ${ }^{296}$.

147. Actualmente, un proyecto que destaca es EULIS, que eleva la transparencia en el mercado inmobiliario transfronterizo y está por lo tanto valorado como el primer paso hacia una armonización de los sistemas registrales ${ }^{297}$. Inicialmente, lo más factible y conveniente sería ampliar el proyecto incluyendo todos los registros europeos, en vez de solamente remitir el solicitante al respectivo sitio web del país, reflejando la información esencial en su propio interfaz. Ello, de todos modos, sin afectar al derecho registral material de los ordenamientos civiles nacionales. Especialmente, gracias a la información adicional sobre el funcionamiento del registro y las instituciones legales propias de un Estado, EULIS puede eliminar obstáculos en la adquisición de un bien inmueble en el extranjero. La información necesaria es más fácilmente consultable y comprensible. Sirve entonces para elevar la seguridad jurídica en este sector y para mejorar el funcionamiento del mercado interior al remover fronteras legales. Todo ello, en su conjunto es apropiado para flexibilizar la decisión de un ciudadano europeo, como del Sr. Müller, de trasladar su residencia a otro país de la Unión Europea y contribuye por consiguiente al ejercicio del derecho a la libre circulación.

148. Por tanto, a largo plazo, el mercado interior solo puede ser perfeccionado si se establece un Registro de la Propiedad Común Europeo, para lo que resulta imprescindible que los Estados Miembros armonicen sus Ordenamientos civiles para promover la integración ${ }^{298}$.

\footnotetext{
${ }^{294}$ C. S. Rupp, “Germanisches Grundbuch und romanisches Register: Harmonisierende Überlegungen”, cit. pp. 567 y 569.

${ }^{295}$ F. Molina Balaguer, “¿Hacia un Registro Europeo de la Propiedad? La lucha contra el blanqueo de capitales: análisis de la situación vigente y de la propuesta de V Directiva anti-blanqueo desde el punto de vista registral”, cit. 2393 y 2428 ; $\mathrm{H}$. Ploeger / B. Van Loenen, "The European Real Estate Market - Transparency, Security and Certainty through registration by EuroTitle", cit. pp. 379 y 387.

${ }^{296}$ J. F. BAUR/ R. STÜRNER, Sachenrecht, cit. $§ 64$ ap. 80.

${ }^{297}$ F. Molina BALAguer, “¿Hacia un Registro Europeo de la Propiedad? La lucha contra el blanqueo de capitales: análisis de la situación vigente y de la propuesta de V Directiva anti-blanqueo desde el punto de vista registral", cit. 2393 y $2428 ; \mathrm{H}$. Ploeger / B. VAn Loenen, "The European Real Estate Market - Transparency, Security and Certainty through registration by EuroTitle", cit. pp. 379 y 387; C. S. Rupp, "Germanisches Grundbuch und romanisches Register: Harmonisierende Überlegungen", cit. pp. 567 y 569.

${ }^{298}$ M. PaschKe / C. Illopoulos, Europäisches Privatrecht - Ein Studienbuch zum Privatrecht der Europäischen Gemeinschaft, cit. pp. 6 y ss.; P. Ulmer, "Vom deutschen zum europäischen Privatrecht?”, 1.
} 